\title{
Optical, Structural, and Dielectric Properties of Composites Based on Thermoplastic Polymers of the Polyolefin and Polyurethane Type and $\mathrm{BaTiO}_{3} \mathrm{Nanoparticles}$
}

\author{
M. Baibarac ${ }^{1, *}$, A. Nila ${ }^{1}$, I. Smaranda ${ }^{1}$, M. Stroe $^{1}$, L. Stingescu ${ }^{1} \mathbb{D}$, M. Cristea $^{1}$, R. C. Cercel ${ }^{1} \mathbb{D}$, A. Lorinczi $^{1}$, \\ P. Ganea ${ }^{1}$, I. Mercioniu ${ }^{2}$, R. Ciobanu ${ }^{3,4}$, C. Schreiner ${ }^{3,4}$, R. G. Garcia ${ }^{5}$ and C. Bartha ${ }^{6}$ (D)
}

1 National Institute of Materials Physics, Laboratory of Optical Processes in Nanostructured Materials, Atomistilor Street 405A, P.O. Box MG-7, R077125 Bucharest, Romania; andreea.nila@infim.ro (A.N.); ion.smaranda@infim.ro (I.S.); malvina@infim.ro (M.S.); luiza.stingescu@infim.ro (L.S.); mirela.cristea@infim.ro (M.C.); radu.cercel@infim.ro (R.C.C.); lorinczi@infim.ro (A.L.); paul.ganea@infim.ro (P.G.)

2 National Institute of Materials Physics, Atomic Structures and Defects in Advanced Materials Laboratory, Atomistilor Street 405A, P.O. Box MG-7, R077125 Bucharest, Romania; imercioniu@infim.ro

3 SC All Green SRL, 8 George Cosbuc, 700470 Iasi, Romania; rciobanu@yahoo.com (R.C.); cschrein@ee.tuiasi.ro (C.S.)

4 Faculty of Electrical Engineering, Department of Electrical Measurements and Materials, Technical University Gh. Asachi Iasi, Bd. Professor Dimitrie Mangeron 67, 70050 Iasi, Romania

5 Izertis, Parque Cientifico Tecnologico, Avda. Del Jardin Botanico, 1345 Edificio Intra, 33203 Gijon, Spain; raquel.garcia@izertis.com

check for

updates

Citation: Baibarac, M.; Nila, A.; Smaranda, I.; Stroe, M.; Stingescu, L.; Cristea, M.; Cercel, R.C.; Lorinczi, A.; Ganea, P.; Mercioniu, I.; et al. Optical, Structural, and Dielectric Properties of Composites Based on Thermoplastic Polymers of the Polyolefin and Polyurethane Type and $\mathrm{BaTiO}_{3}$ Nanoparticles. Materials 2021, 14, 753. https://doi.org/ $10.3390 / \mathrm{ma} 14040753$

Academic Editor: Paweł Głuchowski Received: 30 December 2020

Accepted: 1 February 2021

Published: 5 February 2021

Publisher's Note: MDPI stays neutral with regard to jurisdictional claims in published maps and institutional affiliations.

Copyright: (c) 2021 by the authors. Licensee MDPI, Basel, Switzerland. This article is an open access article distributed under the terms and conditions of the Creative Commons Attribution (CC BY) license (https:/ / creativecommons.org/licenses/by/ $4.0 /)$.
6 National Institute of Materials Physics, Magnetism and Superconductivity Laboratory, Atomistilor Street 405A, P.O. Box MG-7, R077125 Bucharest, Romania; cristina.bartha@infim.ro

* Correspondence: barac@infim.ro; Tel.: +40-21-3690170

\begin{abstract}
In this work, new films containing composite materials based on blends of thermoplastic polymers of the polyurethane (TPU) and polyolefin (TPO) type, in the absence and presence of $\mathrm{BaTiO}_{3}$ nanoparticles (NPs) with the size smaller $100 \mathrm{~nm}$, were prepared. The vibrational properties of the free films depending on the weight ratio of the two thermoplastic polymers were studied. Our results demonstrate that these films are optically active, with strong, broad, and adjustable photoluminescence by varying the amount of TPU. The crystalline structure of $\mathrm{BaTiO}_{3}$ and the influence of thermoplastic polymers on the crystallization process of these inorganic NPs were determined by $X$-ray diffraction (XRD) studies. The vibrational changes induced in the thermoplastic polymer's matrix of the $\mathrm{BaTiO}_{3}$ NPs were showcased by Raman scattering and FTIR spectroscopy. The incorporation of $\mathrm{BaTiO}_{3} \mathrm{NPs}$ in the matrix of thermoplastic elastomers revealed the shift dependence of the photoluminescence (PL) band depending on the $\mathrm{BaTiO}_{3} \mathrm{NP}$ concentration, which was capable of covering a wide visible spectral range. The dependencies of the dielectric relaxation phenomena with the weight of $\mathrm{BaTiO}_{3} \mathrm{NPs}$ in thermoplastic polymers blends were also demonstrated.
\end{abstract}

Keywords: thermoplastic polymers; $\mathrm{BaTiO}_{3} ;$ crystallization processes

\section{Introduction}

Thermoplastic polyurethane (TPU) is a linear elastomer with both non-polar soft and polar hard segments, resulting from the polymerization reaction of diisocyanates having diols with short- and long-chains, respectively [1,2]. The main interest in TPU and its nanocomposites lies in the fabrication of fused filaments, electronic devices, automotive panels, sporting goods, belts, profile, tubes, hoses, and so on [2-4]. Depending on the soft segments, polyester- or polyether-based TPUs are differentiated by abrasion resistance, mechanical properties, hydrolysis resistance, heat aging, injectability, and so on [5-7]. The heat resistance as well as the stiffness of TPU are relatively low and therefore blending them with other polymer matrices is seen as an attractive way to improve these properties $[8,9]$. In this 
context, blends of TPU with insulating macromolecular compounds such as polyamide [10], polylactic acid [11], polycaprolactone [12], and polyolefins [13,14] have been intensively studied. Thermoplastic polyolefin (TPO), known as polyethylene-polyoctene rubbers, is one of the most common and commercial thermoplastic polymers used due to its high rigidity and good chemical resistance $[15,16]$. In TPU:TPO mixtures, the polarity and fragility of the TPO are improved, while the low thermal stability, processability, and some mechanical properties of TPU are considerably enhanced [17-19].

Since 2013, a continuous effort has been devoted in the development of new composites based on $\mathrm{BaTiO}_{3} \mathrm{NPs}$, thermoplastic polymers such as polyvinylidene fluoride (PVDF), and various carbon NPs such as graphene [20] or carbon nanotubes [21] for applications in the field of 3D printing devices [3,22], medical devices [21], and textile fibers [21].

As is well known, $\mathrm{BaTiO}_{3}$ is characterized by a high permittivity of about $10^{5}$ and a low dielectric loss of $\sim 0.05$ [23]. Due to the low polarization ability and high dielectric loss of thermoplastic elastomers, the incorporation of a highly polarizable filler like $\mathrm{BaTiO}_{3}$ NPs in the thermoplastic polymer matrix promotes interfacial (exchange coupling) effects that could significantly enhance the final dielectric performance of the resulting blends for specific electro-active applications [20].

The most widely used solvent mixing techniques for $\mathrm{BaTiO}_{3}$ nanocomposites are based on the solution casting method or in situ polymerization [20]. At the industrial level, the improvement of the manufacturing performance of polymer blends has led to a melting mixing technique using a co-rotating twin screw extruder for the fabrication of $\mathrm{BaTiO}_{3}$ - elastomer nanocomposites [24]. In this context, we note that it has already found a high real dielectric permittivity $\left(\varepsilon_{\mathrm{r}}=5.06\right)$ and a low dielectric loss (less than 0.05) in the case of $\mathrm{BaTiO}_{3}$ incorporated poly(styrene-ethylene/butylene-styrene)-grafted-maleic anhydride elastomers [24] and a significant dielectric permittivity at low frequency (values exceeding $10^{4}$ ) in the $\mathrm{PVDF} / \mathrm{BaTiO}_{3}$ composites [20].

The realization of applications presupposes a good knowledge of the crystallization process of $\mathrm{BaTiO}_{3}$ in the PVDF matrix. [25] In the case of $\mathrm{PVDF} / \mathrm{BaTiO}_{3}$ composites, the addition of inorganic particles to the matrix of the macromolecular compound has been demonstrated to induce a change in the interfacial polarization process and in the crystallization kinetics of heterogenous nucleation when a wider range of polymer melting temperatures in the presence of $\mathrm{BaTiO}_{3} \mathrm{NPs}$ has been reported $[20,25]$. Knowledge of the crystallization process of $\mathrm{BaTiO}_{3} \mathrm{NPs}$ in the matrix of TPU and TPO thermoplastic polymers can open perspectives for new applications such as for 3D and $4 \mathrm{D}$ printed devices $[4,26]$. Therefore, preliminary studies focused on the optical, structural, and dielectric properties of composites based on TPU:TPO blends and $\mathrm{BaTiO}_{3} \mathrm{NPs}$ will be shown in this work.

\section{Materials and Methods}

\subsection{Materials}

Thermoplastic elastomers (i.e., TPU and TPO including a hardener, which corresponds to polydimethylsiloxane, marketed under the name of Sylgard TM 186 Silicone elastomer curing agent) were purchased from the Elastollan-BASF Chemical Company (Cleveland, $\mathrm{OH}, \mathrm{USA}$ ). $\mathrm{BaTiO}_{3}$ nanopowder, $\mathrm{N}, \mathrm{N}^{\prime}$-dimethyl formamide (DMF), and $\mathrm{C}_{2} \mathrm{H}_{5} \mathrm{OH}$ were purchased from Sigma Aldrich (St. Louis, MO, USA).

\subsection{The Preparation of TPU:TPO Films in the Absence and Presence of $\mathrm{BaTiO}_{3} \mathrm{NPS}$}

The TPU:TPO blends were prepared as free films as follows. In the first stage, a solution of TPU in dimethylformamide (DMF) $(0.5 \mathrm{~g} / 8 \mathrm{~mL})$ and another of TPO in $\mathrm{C}_{2} \mathrm{H}_{5} \mathrm{OH}$ $(0.5 \mathrm{~g} / 10 \mathrm{~mL})$, to which was added $0.1 \mathrm{~g}$ of the TPO hardener in $2 \mathrm{~mL}$ DMF, were prepared under ultrasonication. After ultrasonically mixing them for $5 \mathrm{~min}$, the resulting solution was placed in a Petri dish and dried for $2 \mathrm{~h}$ at $100{ }^{\circ} \mathrm{C}$. The resulting film was peeled off the Petri glass and labeled as a TPU:TPO 1:1 blend, this being dried under vacuum to constant weight. Using this protocol and changing the mass ratio of the two thermoplastic polymers, 
five other free films labeled as blends of TPU:TPO 1:3, TPU:TPO 1:2, TPU:TO 2:1, TPU:TPO 4:1, and TPU:TPO 6:1 were prepared. The thickness of all blends was ca. $43 \mu \mathrm{m}$.

The composites based on the TPU:TPO 1:1 blends and $\mathrm{BaTiO}_{3} \mathrm{NPs}$ were prepared as described above, with the only difference being that after mixing the TPU and TPO solutions, the various weights of the inorganic particles (i.e., $0.05,0.1,0.23$, and $0.3 \mathrm{~g}$ ) were added under ultrasonication for $10 \mathrm{~min}$. After the thermal treatment at $100{ }^{\circ} \mathrm{C}$ and drying under vacuum to constant weight, films labeled as composites based on TPU:TPO $1: 1$ and $\mathrm{BaTiO}_{3}$, having the concentration of inorganic NPs equal to $6.25,12,25$, and $30 \mathrm{wt} . \%$, respectively, were obtained. As the $\mathrm{BaTiO}_{3} \mathrm{NP}$ concentration in the polymer weight increased from $6.25,12,25$, and $30 \mathrm{wt} . \%$, the thicknesses of the films changed to $\sim 43.4,44.0,44.6 \mathrm{~m}$ and $45 \mu \mathrm{m}$, respectively.

\subsection{Microscopy Analysis}

Scanning electron microscopy (SEM) images of $\mathrm{BaTiO}_{3} \mathrm{NPs}_{\mathrm{N}}$ and the composites with the PTU:TPO blends were recorded with a scanning electron microscope, model Tescan Lyra III XMU (Libušina tř. 21623 00, Brno-Kohoutovice, Czech Republic).

$\mathrm{BaTiO}_{3} \mathrm{NPs}$ were studied by high-resolution transmission electron microscopy (HRTEM) (JEOL Ltd., Tokyo, Japan). In this order, a suspension of $\mathrm{BaTiO}_{3} \mathrm{NPs}$ in $\mathrm{C}_{2} \mathrm{H}_{5} \mathrm{OH}$ was prepared and successively transferred onto a copper grid coated with an amorphous carbon support. HRTEM images of the $\mathrm{BaTiO}_{3}$ NPs were recorded with a JEOL JEM ARM $200 \mathrm{~F}$ electron microscope working at $200 \mathrm{keV}$.

\subsection{X-ray Diffraction Analysis}

X-ray diffraction (XRD) patterns of TPU, TPO, $\mathrm{BaTiO}_{3}$, and their composites were performed in a theta-theta configuration in the angular range of $2 \theta=5^{\circ}-65^{\circ}$ with a Bruker D8 Advance diffractometer (Bruker, Hamburg, Germany).

\subsection{Fourier Transform Infrared (FTIR) Spectroscopic Analysis}

The IR spectra of TPU, TPO, $\mathrm{BaTiO}_{3}$, and their composites were recorded using a FTIR spectrophotometer, Vertex 80 model from Bruker (Billerica, MA, USA) with a resolution of $2 \mathrm{~cm}^{-1}$.

\subsection{FT-Raman Spectroscopic Analysis}

The Raman spectra of TPU, TPO, $\mathrm{BaTiO}_{3}$, and their composites were recorded with a FT-Raman spectrophotometer, RFS $100 \mathrm{~S}$ model, from Bruker (Ettlingen, Germany) with a resolution of $1 \mathrm{~cm}^{-1}$.

\subsection{Photoluminescence Analysis}

The photoluminescence (PL) spectra of TPU, TPO, $\mathrm{BaTiO}_{3}$, and their composites were recorded with a Fluorolog-3 spectrophotometer, FL3-2.2.1 model, from Horiba Jobin Yvon (Palaiseau, France).

\subsection{Dielectric Properties}

The dielectric properties of composites based on the TPU:TPO blends and $\mathrm{BaTiO}_{3}$ NPs were examined using dielectric spectroscopy (DS) with the equipment having a high resolution Alpha-A Analyzer from NOVOCONTROL GmBH. The electrical properties were determined at room temperature with the frequency being between $0.01 \mathrm{~Hz}$ and $10 \mathrm{MHz}$ and the alternating voltage having the value of $0.3 \mathrm{~V}$. The samples were in the form of platelets with a diameter of approximately $13 \mathrm{~mm}$ and their thicknesses varied between $0.095 \mathrm{~mm}$ and $0.160 \mathrm{~mm}$. The samples were placed between two circular metal electrodes in a capacitor configuration with plane-parallel armatures. 


\subsection{Differential Scanning Calorimetry (DSC) Analysis}

Differential scanning calorimetry (DSC) measurements were performed with a DSC 204 F1 type from Netzsch (Selb, Germany). The experiments were conducted at room temperature to $500{ }^{\circ} \mathrm{C}$ in an inert atmosphere of helium $(40 \mathrm{~mL} / \mathrm{min}$ flow gaze rate) and a heating rate of $5{ }^{\circ} \mathrm{C} / \mathrm{min}$. The samples were sealed by pressing and an empty $\mathrm{Al}$ crucible $=$ was used as the reference. The accuracy of the heat flow measurements was $\pm 0.001 \mathrm{~mW}$.

\section{Results and Discussions}

3.1. Morphological and Structural Properties of the Composites Based on the TPU:TPO Blends and $\mathrm{BaTiO}_{3} \mathrm{NPS}$

The SEM micrograph of the films based on the TPU:TPO 1:1 blends and the $\mathrm{BaTiO}_{3}$ NPs are shown in Figure 1. At present, it is necessary to note that TPO is a material that combines crystalline or semi-crystalline thermoplastic components made of polyolefins (hard domain) with amorphous elastomeric components of polyethylene-polyoctene rubbers (soft structure) [27]. Figure 1a reveals a complex morphology consisting of continuous phases of TPO and TPU films, accompanied by a discrete phase that is randomly distributed. Taking into account the TPU composition, it is composed of hard polar segments (urethane component) and soft less-polar segments (long-chain diol) with glassy and rubbery characteristics, respectively. Such a structure is described by a high and low glass transition temperature that induces the thermodynamic incompatibility between hard and soft segments. In this context, the self-assembly of hard segments through physical bonds causes the Gibbs free energy of the film to become positive, inducing a two-phase separation with the formation of a hard-micro-domain aggregation of the urethane segments [28]. Simultaneously, a discrete phase is expected to appear in the TPO film due to a crystalline form of isotactic polypropylene, most often used as the polyolefin thermoplastic phase in the TPO composition [27]. Consequently, the discrete phases of approximately spherical shape belong to both TPO and TPU and they are randomly distributed to form the cross-physical contacts between the amorphous segments of TPU and TPO. A uniform dispersion of $\mathrm{BaTiO}_{3} \mathrm{NPs}$ in the structure of thermoplastic polymers is observed as the amount of $\mathrm{BaTiO}_{3}$ increases. Most likely, the urethane polar group of TPU ensures good interfacial adhesion and a better dispersion of the polarizable microparticles of $\mathrm{BaTiO}_{3}$ in the TPU:TPO blends with the increase in $\mathrm{BaTiO}_{3}$ concentration.

In order to show additional information concerning the size of the inorganic NPs, Figure 2 shows the HRTEM image of the $\mathrm{BaTiO}_{3}$ NPs. The analysis of Figure 2 indicates that in the case of the particle count equal to 100, values of the minimum, maximum, and mean size of the $\mathrm{BaTiO}_{3} \mathrm{NPs}$ equaled $30.04 \pm 9.89 \mathrm{~nm}, 79.93 \pm 9.89 \mathrm{~nm}$, and $53.35 \pm 9.89$ $\mathrm{nm}$, respectively. 


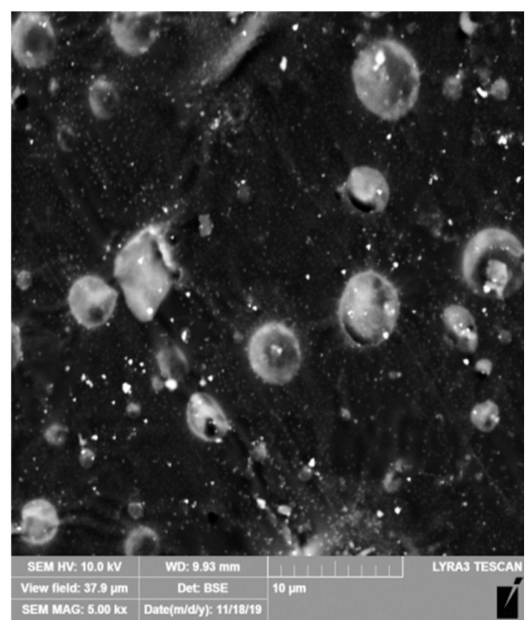

(a)

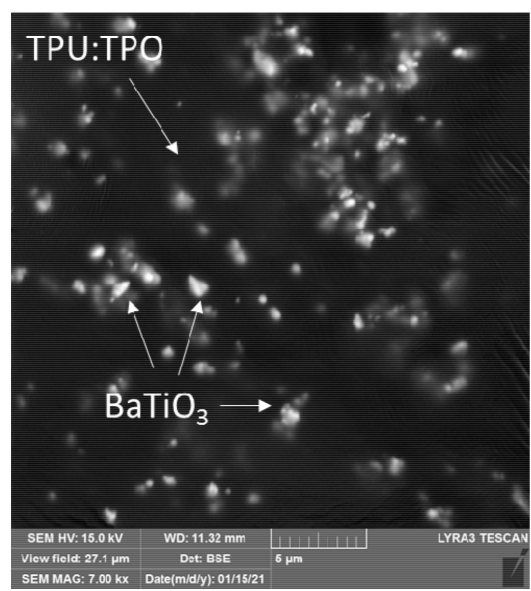

(c)

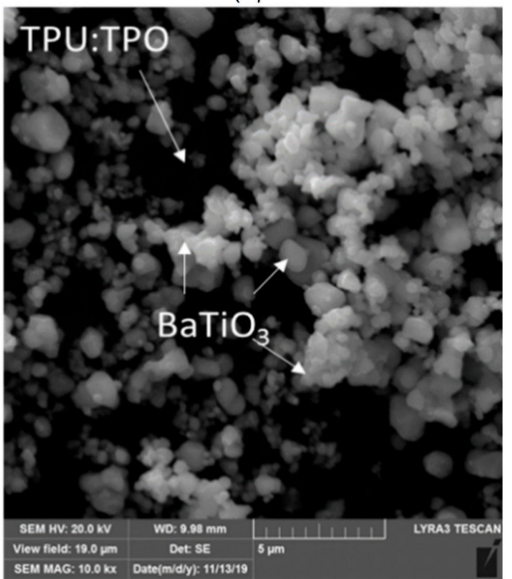

(e)

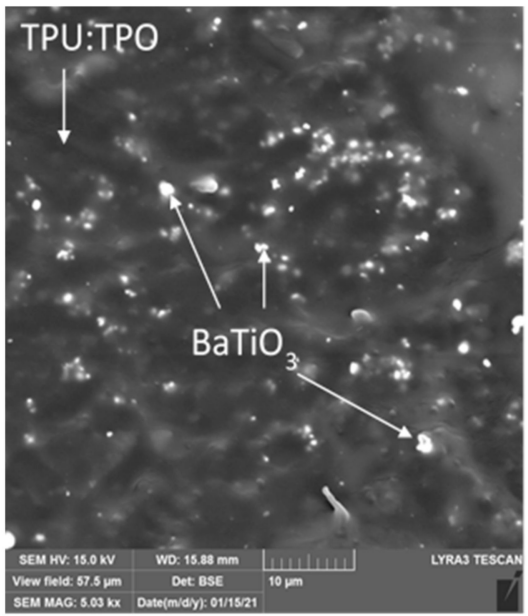

(b)

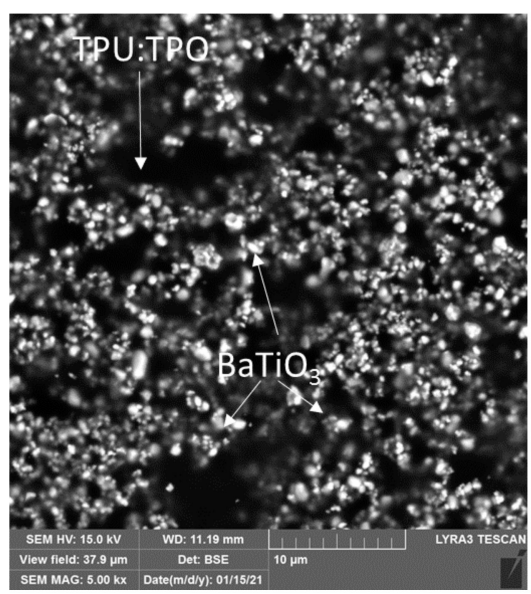

(d)

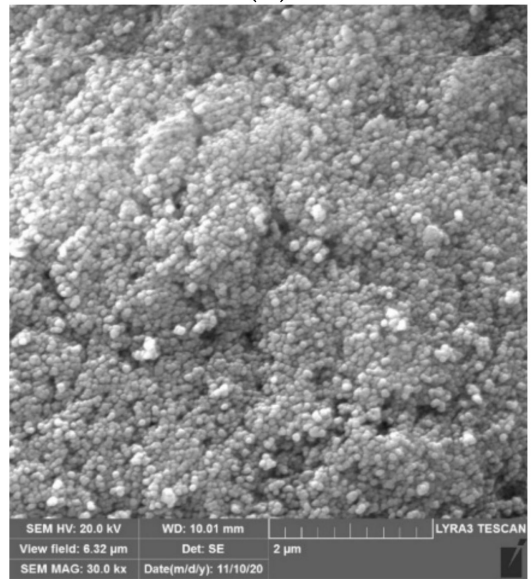

(f)

Figure 1. Scanning electron microscopy (SEM) images of TPU:TPO 2:1 films in the absence (a) and in the presence of the $\mathrm{BaTiO}_{3} \mathrm{NPs}$, when the inorganic compound concentration is equal to $6.25 \mathrm{wt} . \%$ (b), 12 wt.\% (c), 25 wt. \% (d), and 30 wt.\% (e). SEM image of $\mathrm{BaTiO}_{3} \mathrm{NPs}$ with the mean size equal to $53.35 \pm 9.89 \mathrm{~nm}(\mathbf{f})$. 


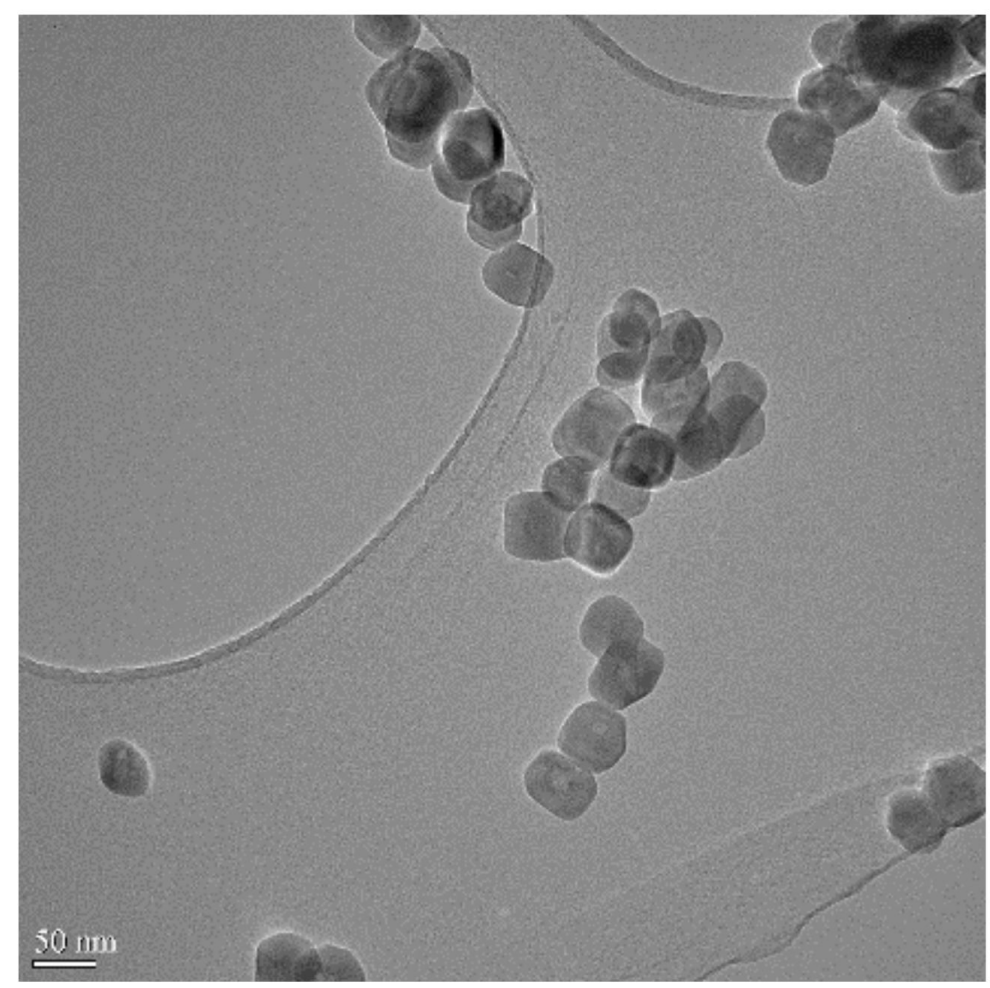

Figure 2. High-resolution transmission electron microscopy (HRTEM) images of the $\mathrm{BaTiO}_{3} \mathrm{NPs}_{\text {. }}$

The XRD spectra of $\mathrm{BaTiO}_{3}, \mathrm{TPU}, \mathrm{TPO}$, and their composites are shown in Figure 3. The XRD pattern of $\mathrm{BaTiO}_{3}$ is shown in Figure $3 \mathrm{a}$, and revealed the crystalline tetragonal phase of $\mathrm{BaTiO}_{3}$ according to the standard International Centre for Diffraction Data (ICCD) database (PDF 04-016-2042) and the main diffraction peaks appeared at $2 \theta$ equal to $22.2^{\circ}, 31.5^{\circ}, 38.9^{\circ}, 45.4^{\circ}, 51^{\circ}$, and $56.3^{\circ}$, these being assigned to the crystalline planes (001), (110), (111), (002), (210), and (211), respectively. The XRD patterns of the two thermoplastic polymers (i.e., TPO and TPU) presented an amorphous structure highlighted by a non-crystalline board peak having the maximum $2 \theta$ equal to $19.9^{\circ}$ (Figure $3 \mathrm{~b}$ ) and $19.6^{\circ}$ (Figure $3 c$ ), respectively. In addition, Figure $3 b$ shows a series of small maxima, most probably corresponding to a minor ordered phase formed inside the TPU polymer. The most prominent maximum from this series was the first one, at around $29.3^{\circ}$, followed by smaller ones at $35.9^{\circ}, 39.3^{\circ}, 43.1^{\circ}$, and $47.3^{\circ}$. These data correlated rather well with a TPU diffraction pattern reported in [29]. In contrast with TPU, significant differences were observed for the XRD pattern of TPO in the $2 \theta$ angular domain between $40^{\circ}$ and $65^{\circ}$. The presence of peaks from $2 \theta$ equal to $44.3^{\circ}$ and $64.5^{\circ}$ in the XRD pattern of TPO have also been reported by Z.J. Zhang et al. [30]. These can be correlated with both propylene chains of TPO (hard segments) and carbon black, which is incorporated in the TPO fabrication as an additive in order to stabilize the membrane against UV irradiation or as a filler to increase the hardness of the membrane [31].

As expected, the XRD pattern of the TPU:TPO 2:1 blend (Figure 3d) contained all the peaks of the two thermoplastic polymers. Figure 3e shows the XRD pattern of the composite based on the TPU:TPO 2:1 blend and $\mathrm{BaTiO}_{3} \mathrm{NPs}_{\mathrm{S}}$ when the inorganic compound concentration was equal to $30 \mathrm{wt}$ \%. In this last case, a sum effect of the three constituents, without disturbing the tetragonal structure of the $\mathrm{BaTiO}_{3} \mathrm{NPs}$, can be remarked. 


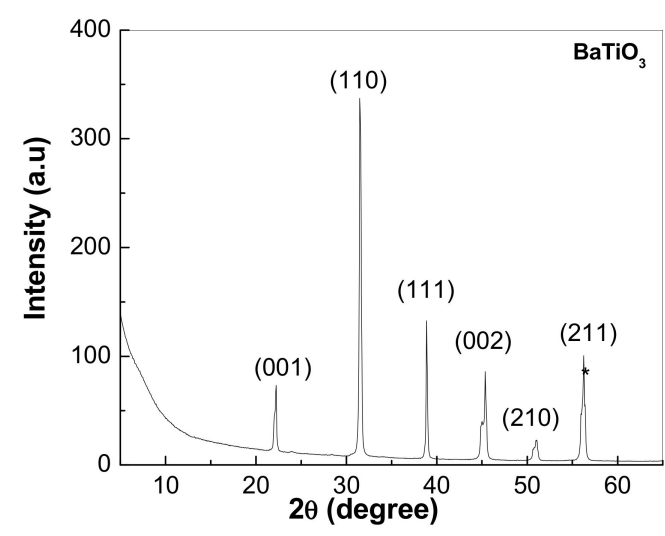

(a)

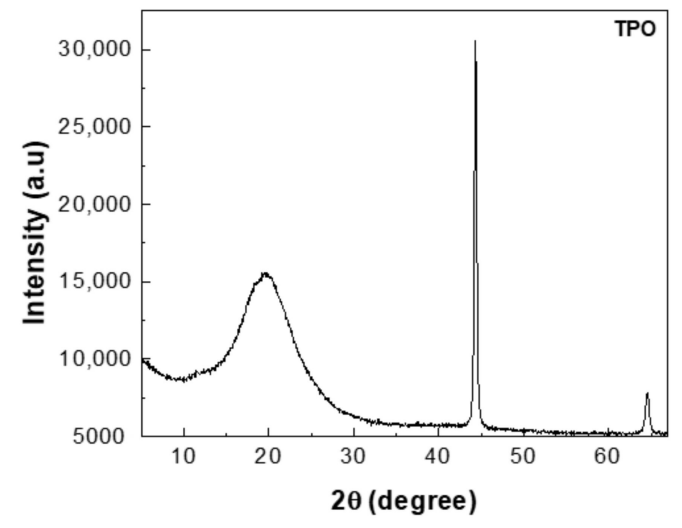

(c)

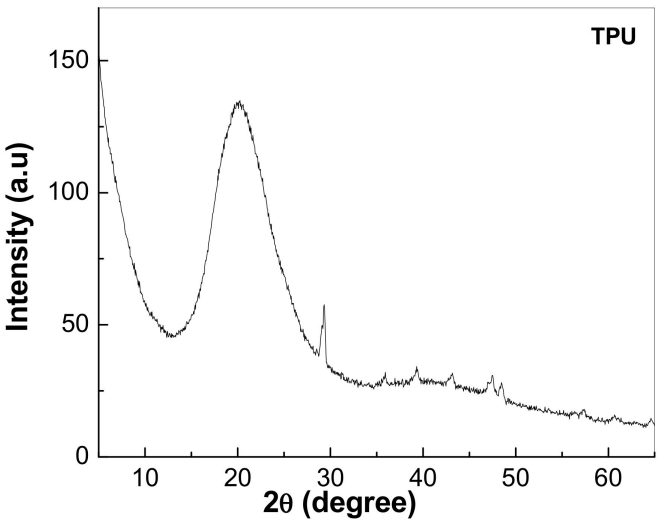

(b)

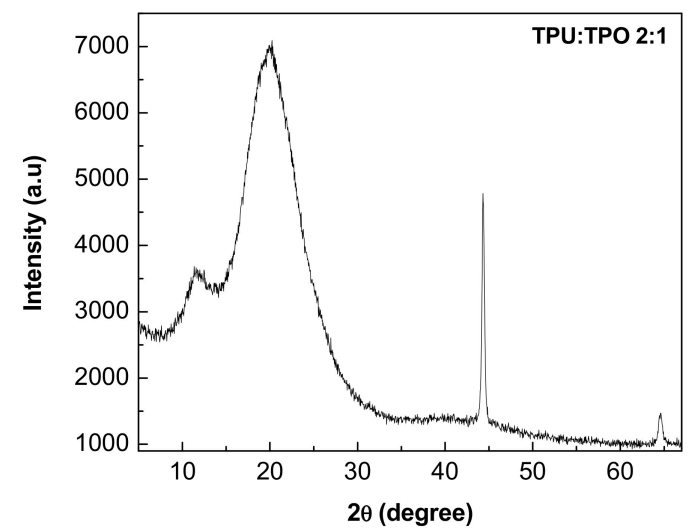

(d)

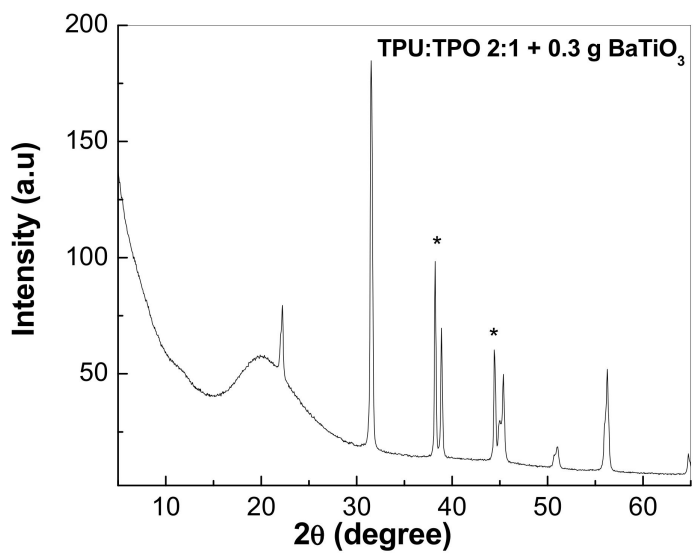

(e)

Figure 3. X-ray diffraction (XRD) spectra of $\mathrm{BaTiO}_{3} \mathrm{NPs}(\mathbf{a})$, thermoplastic polyurethane (TPU) (b), thermoplastic polyolefin (TPO) (c), TPU:TPO 2:1 blend (d), and the composite based on the blend TPU:TPO 2:1 and the $\mathrm{BaTiO}_{3} \mathrm{NPs}$ when the inorganic compound concentration was equal to $30 \mathrm{wt} . \%$ (e). The peaks, marked with * at $38.3^{\circ}$ and $44.5^{\circ}$ belong to the sample holder of the diffractometer.

\subsection{Vibrational Properties of the Composites Based on the TPU:TPO Blends and $\mathrm{BaTiO}_{3} \mathrm{NPS}_{\mathrm{S}}$}

Figure 4 shows the Raman spectra of films based on the TPU and TPO thermoplastic polymers as well as their blends. According to Figure 4, the Raman spectrum of TPO can be characterized by lines located at $2908-2968 \mathrm{~cm}^{-1}$, assigned to the $\mathrm{C}-\mathrm{H}$ stretching vibrational mode [32]. In the case of the TPU:TPO blend, Figure 4 highlights the following Raman lines located at 1300, 1440,1618, and $2864 \mathrm{~cm}^{-1}$, which are attributed to the vibrational modes of deformation of $\mathrm{CH}$-urethane amide, symmetrical stretch of $\mathrm{N}=\mathrm{C}=\mathrm{O}+\mathrm{CH}_{2}$ 
deformation, aromatic stretching structure, and $\mathrm{CH}$ stretching in the aromatic structure, respectively [33,34].

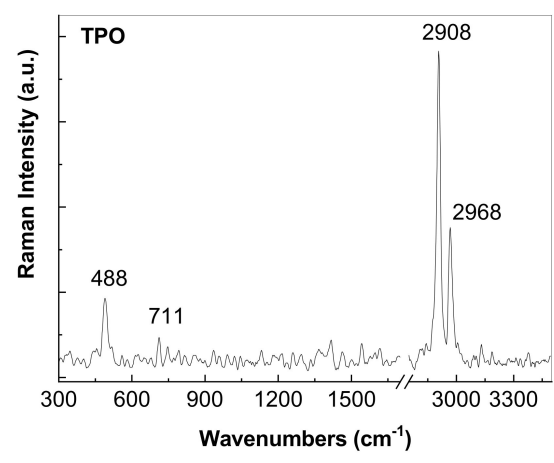

(a)

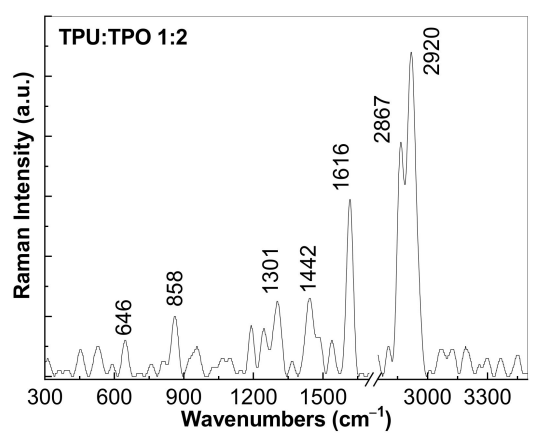

(c)

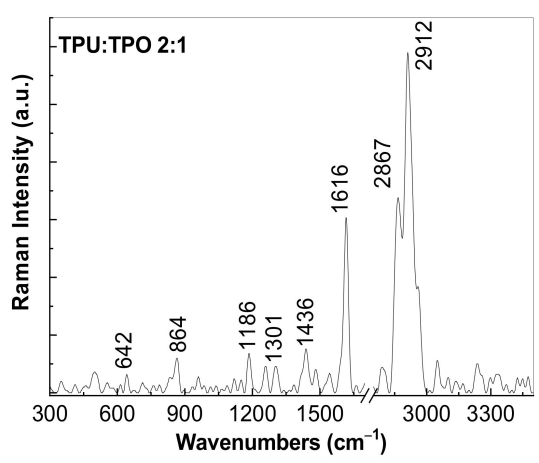

(e)

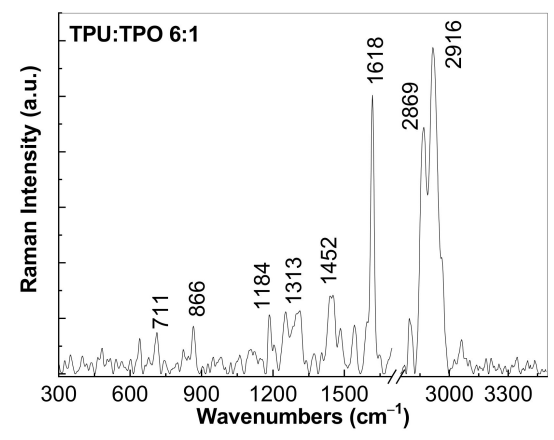

(g)

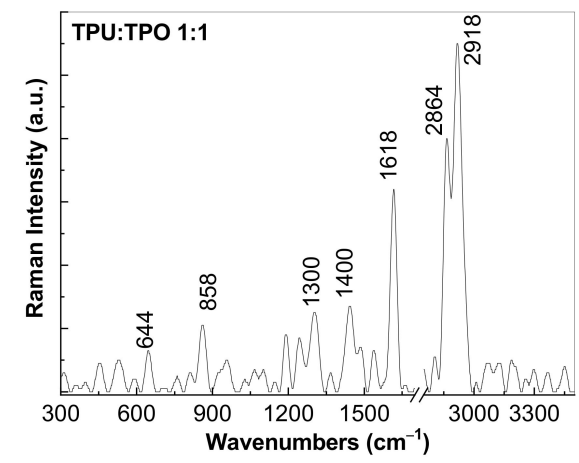

(b)

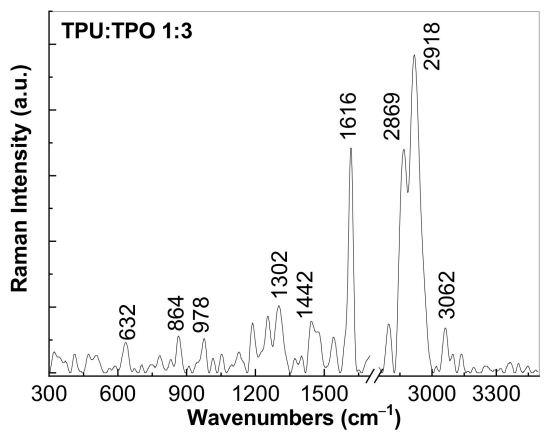

(d)

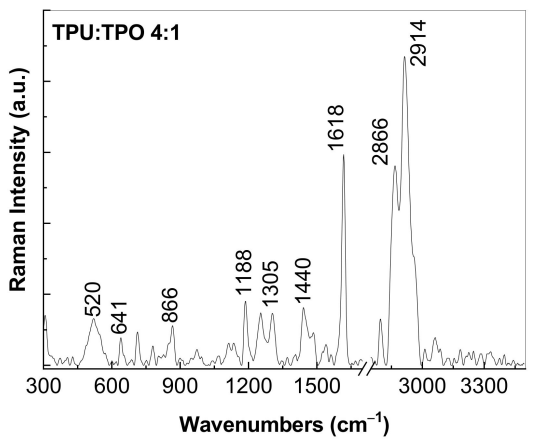

(f)

Figure 4. Raman spectra of the thermoplastic polymers: TPO (a), TPU:TPO 1:1 (b), TPU:TPO 1:2 (c), TPU:TPO 1:3 (d), TPU:TPO 2:1 (e), TPU:TPO 4:1 (f), and TPU:TPO 6:1 (g). 
Increasing the TPU weight in the films based on the TPU:TPO blends led to: (i) a gradual shift of the Raman line belonging to TPO from $2908 \mathrm{~cm}^{-1}$ (Figure 4a) to $2912 \mathrm{~cm}^{-1}$ (Figure 4e), $2914 \mathrm{~cm}^{-1}$ (Figure 4f), $2916 \mathrm{~cm}^{-1}$ (Figure 4g), and $2918 \mathrm{~cm}^{-1}$ (Figure 4b); and (ii) a change in the ratio between the relative intensities of the Raman lines located at $1616 \mathrm{~cm}^{-1}$ and $2912-2916 \mathrm{~cm}^{-1}$ in favor of the first line. Figure 5e highlights that the main Raman lines of the $\mathrm{BaTiO}_{3}$ peaked at $268,308,520$, and $715 \mathrm{~cm}^{-1}$, these being assigned to the vibrational modes $\mathrm{A}_{1}(\mathrm{TO}), \mathrm{E}(\mathrm{TO}+\mathrm{LO}), \mathrm{A}_{1}(\mathrm{TO})$, and $\mathrm{E}(\mathrm{LO})$, respectively [35].

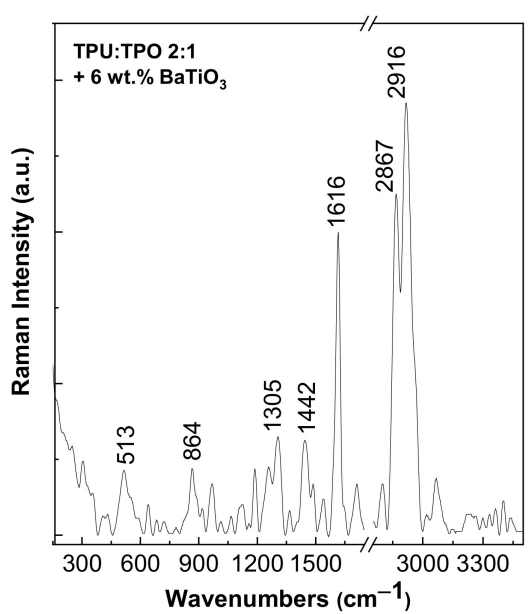

(a)

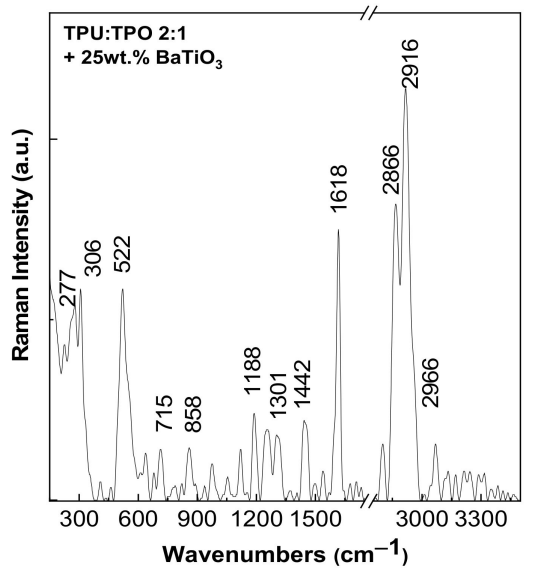

(c)

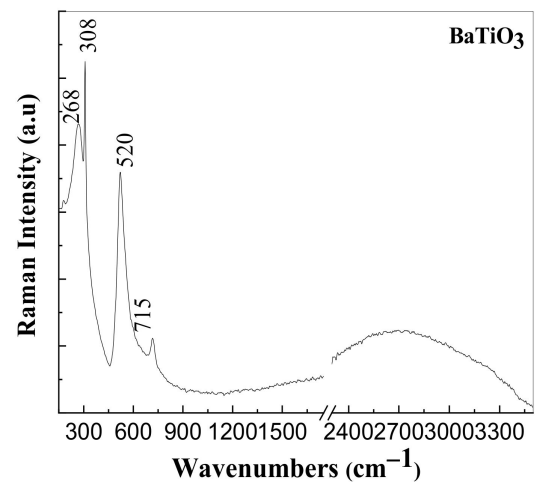

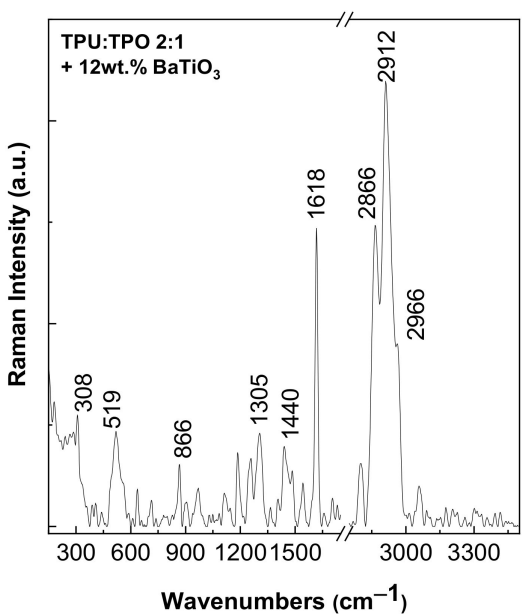

(b)

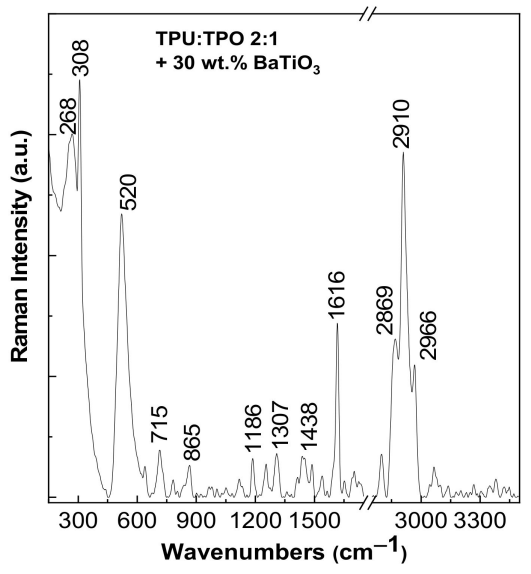

(d)

(e)

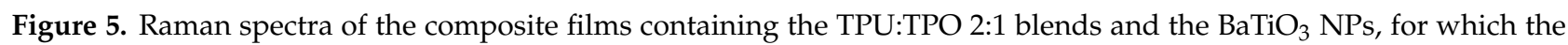
inorganic compound concentration was equal to 6.25 wt.\% (a), 12 wt.\% (b), 25 wt.\% (c), and 30 wt.\% (d). The Raman spectrum of $\mathrm{BaTiO}_{3}$ is shown in (e). 
According to Figure 5, depending on the $\mathrm{BaTiO}_{3}$ concentration in the film containing the TPU:TPO 2:1 blends, we observed: (i) a gradual increase in the intensity of the Raman lines related to the guest inorganic particle as their concentration increased; (ii) a change in the position of the Raman line from $520 \mathrm{~cm}^{-1}$ (Figure 5e) to $513 \mathrm{~cm}^{-1}$ (Figure 5a) at a lower concentration of $\mathrm{BaTiO}_{3}$ in the TPU:TPO 2:1 blend (6 wt.\%); (iii) an up-shift of the Raman line from $1300 \mathrm{~cm}^{-1}$ (Figure $4 \mathrm{~b}$ ) to $1307 \mathrm{~cm}^{-1}$ (Figure $5 \mathrm{~d}$ ) as the $\mathrm{BaTiO}_{3}$ concentration increased in the films' structure; and (iv) a down-shift of the Raman line at $2918 \mathrm{~cm}^{-1}$ (Figure $4 \mathrm{~b}$ ) to $2910 \mathrm{~cm}^{-1}$ (Figure 5d). These changes suggest an adsorption of the thermoplastic polymers on the surface of $\mathrm{BaTiO}_{3} \mathrm{NPs}$ via C-H bonds of the TPU amide groups. Complementary information on the vibrational properties of $\mathrm{BaTiO}_{3}, \mathrm{TPU}, \mathrm{TPO}$, and their composites are presented by IR spectroscopy. According to Figure 6, the main IR absorption bands of TPO are located at 787, 1009, 1258, and $2963 \mathrm{~cm}^{-1}$ (Figure 6a); the absorption band of $787 \mathrm{~cm}^{-1}$ can be attributed to the complex vibration mode of $\mathrm{CH}_{2}$ rock + C-C chain stretching $+\mathrm{CH}$ bending [36], and the bands of 1009 and $1258 \mathrm{~cm}^{-1}$ correspond to the $-\mathrm{CH}_{3}$ rocking vibrational modes and $\mathrm{CH}$ bending vibrations, respectively [37].
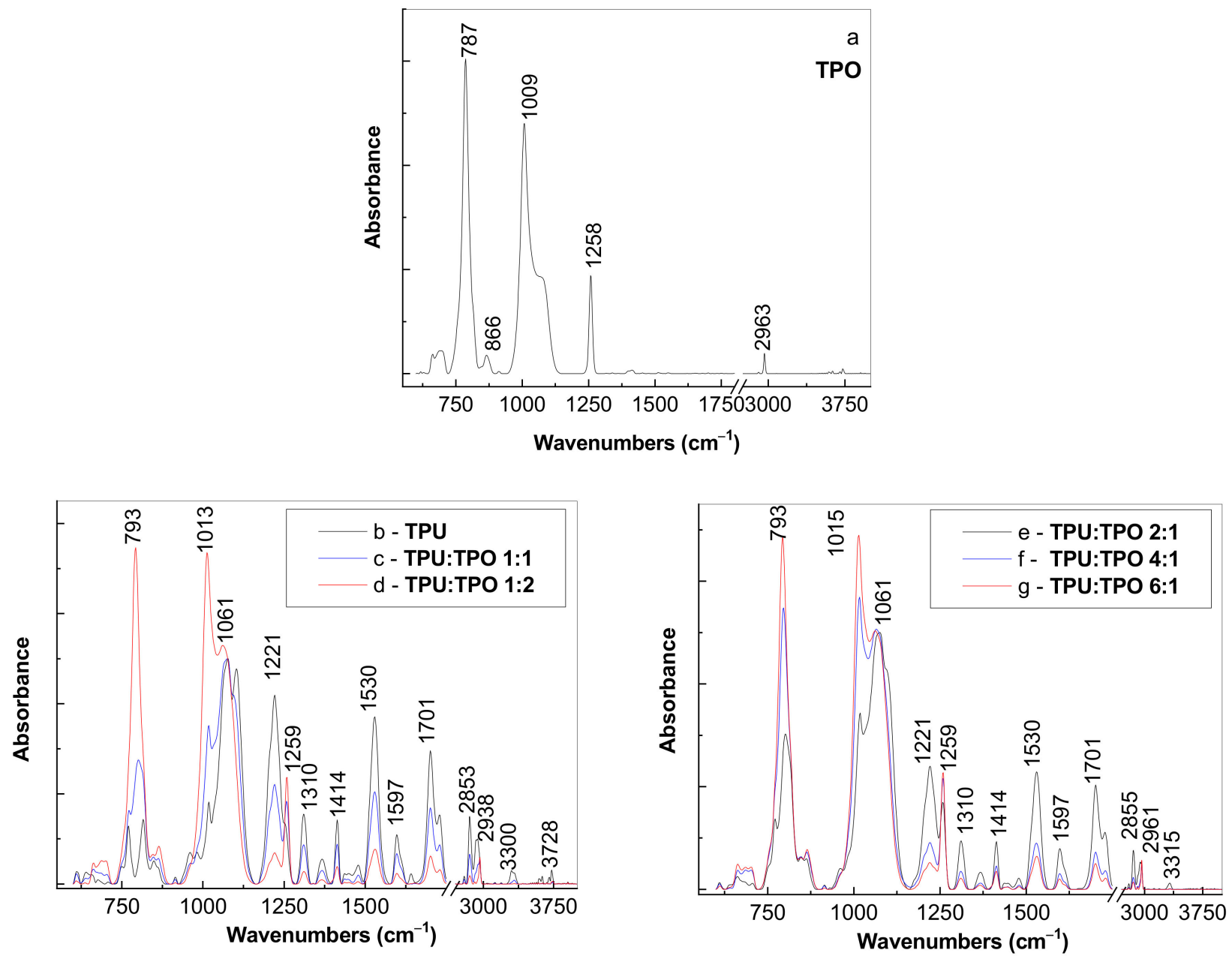

Figure 6. Fourier transform infrared (FTIR) spectra of TPO (a), TPU (b), TPU:TPO 1:1 (c), TPU:TPO 1:2 (d), TPU:TPO 2:1 (e), TPU:TPO 4:1 (f), TPU:TPO 6:1 (g).

The last absorption band at $1258 \mathrm{~cm}^{-1}$ can be assigned to the asymmetric stretching vibration modes of the $\mathrm{CH}_{3}$ - groups [37] and the stretching vibrations of the $\mathrm{C}-\mathrm{H}$ bonds [32]. The TPUs are located at 816, 1076-1103, 1221, 1310, 1414, 1530, 1597, 1701-1730, 2853-2938, and $3300-3728 \mathrm{~cm}^{-1}$ (Figure 6b). According to the studies reported thus far, the IR band of bending vibrational modes of $\mathrm{N}-\mathrm{H}$ can be observed at $816 \mathrm{~cm}^{-1}$, while the absorption 
bands from 1000-1150, 1202, 1597, and 3100-3600 $\mathrm{cm}^{-1}$ are attributed to the vibrational modes of stretching $\mathrm{C}(\mathrm{O})-\mathrm{OC}, \mathrm{CO}$ stretching in the ether group, $\mathrm{C}-\mathrm{C}+\mathrm{C}=\mathrm{C}$ in the benzene ring, and the stretching vibrational modes of the NH group, respectively [38-40]. The IR bands of 2853 and $2938 \mathrm{~cm}^{-1}$ are attributed to the anti-symmetrical and symmetrical vibrational modes of the $\mathrm{CH}$ bonds, respectively $[41,42]$. The absorption band located at $1701 \mathrm{~cm}^{-1}$ is assigned to the hydrogen-linked urethane carbonyl group $(C=O)[43,44]$, while the free carbonyl vibration modes are attributed to the IR band located at $1730 \mathrm{~cm}^{-1}$ [41-45]. Moreover, the IR band at $3300 \mathrm{~cm}^{-1}$ is associated with the NH group [45], which means that a partial inter- and intra-molecular hydrogen linkage of NH group is made between the adjacent urethane segments. The advantage of the inter-molecular hydrogen bonds between neighboring polyurethane groups consists of more stable and segregation-free TPU segments. Due to the interconnected effects between TPU and TPO, in the TPU/TPO blend (Figure 6c,d), the IR absorption band at $3300 \mathrm{~cm}^{-1}$ decreased completely in the TPU:TPO 1:2 blend, while the IR vibrational modes of the hydrogen bond-CO group showed a continuous decrease in its corresponding IR band located at $1701 \mathrm{~cm}^{-1}$ with an increase in the TPO concentration in the TPU:TPO blend. This means that the hydrogen bonds between the adjacent urethane groups are significantly suppressed by the surrounding polyolefins segments of TPO, which are likely similar to a wrapped membrane that isolates the $\mathrm{CO}$ and $\mathrm{NH}$ groups. According to Figure 6, as the mass ratio of the two polymers is changed in favor of TPU, a modification in the ratio between the absorbance of the IR bands from 1009 and $1076 \mathrm{~cm}^{-1}$ can be observed. With an increase in the $\mathrm{BaTiO}_{3} \mathrm{NP}$ concentration in the TPU:TPO 1:1 blend, the following changes can be reported: (i) a downshift of the IR bands from 800,1018, and $1074 \mathrm{~cm}^{-1}$ (Figure 6e) to 795, 1013, and $1061 \mathrm{~cm}^{-1}$ (Figure 7c); (ii) a gradual increase of the ratio between the absorbance of the two IR bands situated in the spectral range $950-1100 \mathrm{~cm}^{-1}$ from 0.71 (Figure 6c) to 1.4 (Figure 7c); (iii) a progressive decrease of the ratio between the absorbance of the IR bands peaked at 1221 and $1257 \mathrm{~cm}^{-1}$ from 1.2 (Figure 6c) to 0.74 (Figure 7a), 0.63 (Figure 7b) and 0.22 (Figure 7c); (iv) a decrease in the absorbance of the IR bands situated in the spectral range 1400-1730 $\mathrm{cm}^{-1}$ (Figures $6 \mathrm{c}$ and 7 ). Such a variation can also be observed in Figure 6, when the mass ratio between the two thermoplastic polymers changed. This variation can be explained by taking into account an exchange reaction between TPU and TPO, as shown in Scheme 1.

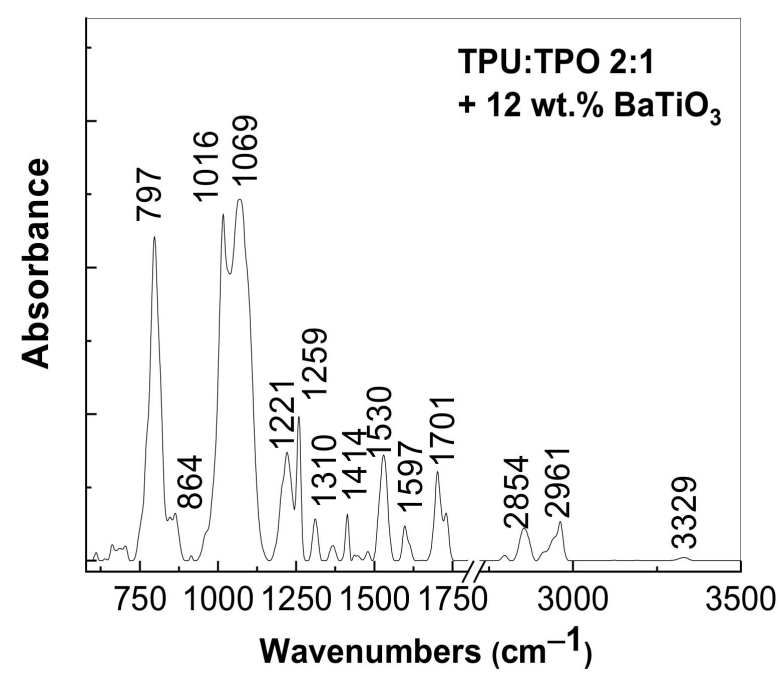

(a)

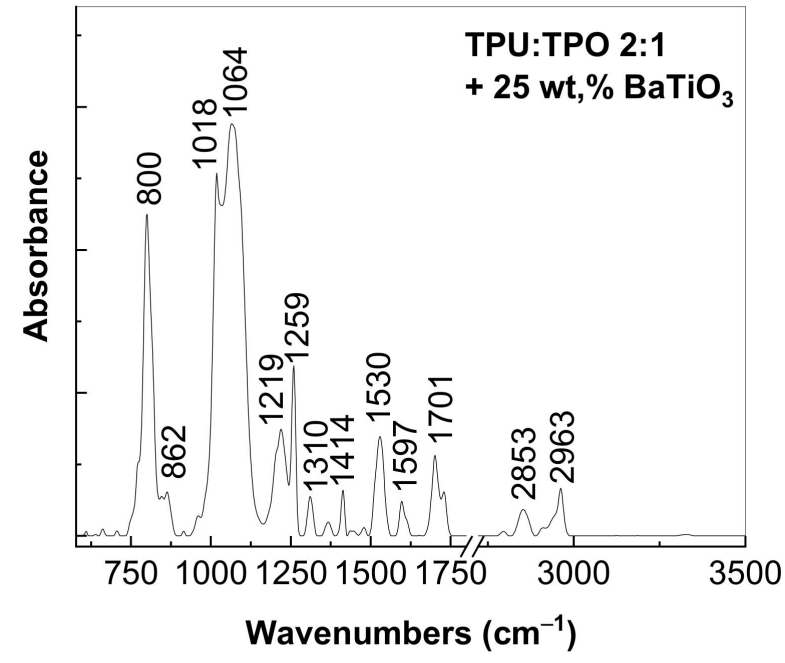

(b)

Figure 7. Cont. 


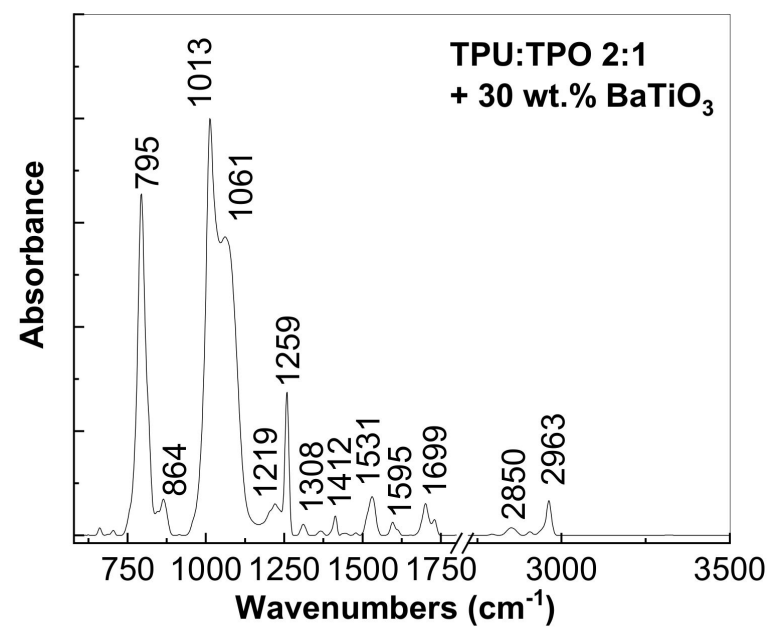

(c)

Figure 7. Fourier transform infrared (FTIR) spectra of the films based on composites containing TPU:TPO 2:1 blends and $\mathrm{BaTiO}_{3} \mathrm{NPs}$ with the inorganic compound concentration being equal to $12 \mathrm{wt} . \%$ (a), $25 \mathrm{wt}$. \% (b), and $30 \mathrm{wt}$. \% (c).

$$
\begin{aligned}
& \left.\left[\mathrm{O}\left(\mathrm{CH}_{2}\right)_{4} \mathrm{O}-\mathrm{CO}\left(\mathrm{CH}_{2}\right)_{4} \mathrm{COO}\left(\mathrm{CH}_{2}\right)_{4} \mathrm{O}\right)_{\mathrm{n}} \mathrm{CONHC}_{6} \mathrm{H}_{4} \mathrm{CH}_{2} \mathrm{C}_{6} \mathrm{H}_{4} \mathrm{NHCO}\right]_{\mathrm{m}}
\end{aligned}
$$

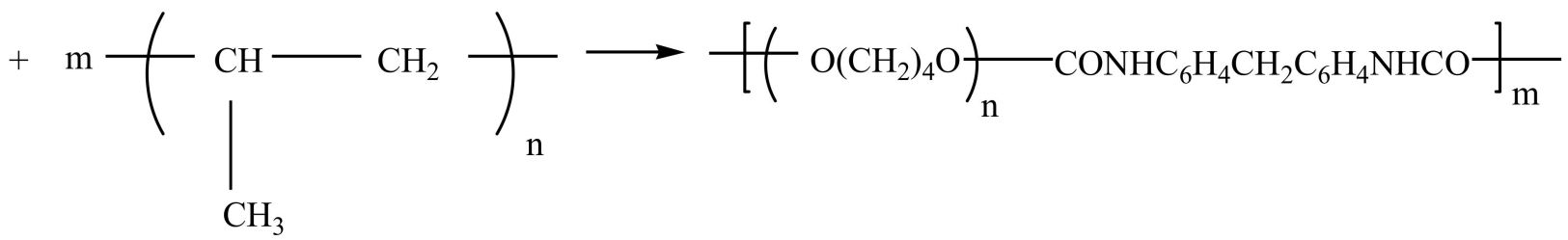

$$
\begin{aligned}
& +-\left[\mathrm{O}\left(\mathrm{CH}_{2}\right)_{4} \mathrm{O}-\left(\mathrm{CO}\left(\mathrm{CH}_{2}\right)_{4} \mathrm{CO}-\mathrm{CH}\left(\mathrm{CH}_{3}\right) \mathrm{CH}_{2}\right)_{\mathrm{n}}\right]_{\mathrm{m}}
\end{aligned}
$$

Scheme 1. The exchange reaction of TPU in the presence of the polypropylene form of TPO.

Returning at Figure 7, the above variations indicate a chemical interaction between TPU and $\mathrm{BaTiO}_{3}$ NPs, which can be described as an exchange reaction that takes place according to Scheme 2 .

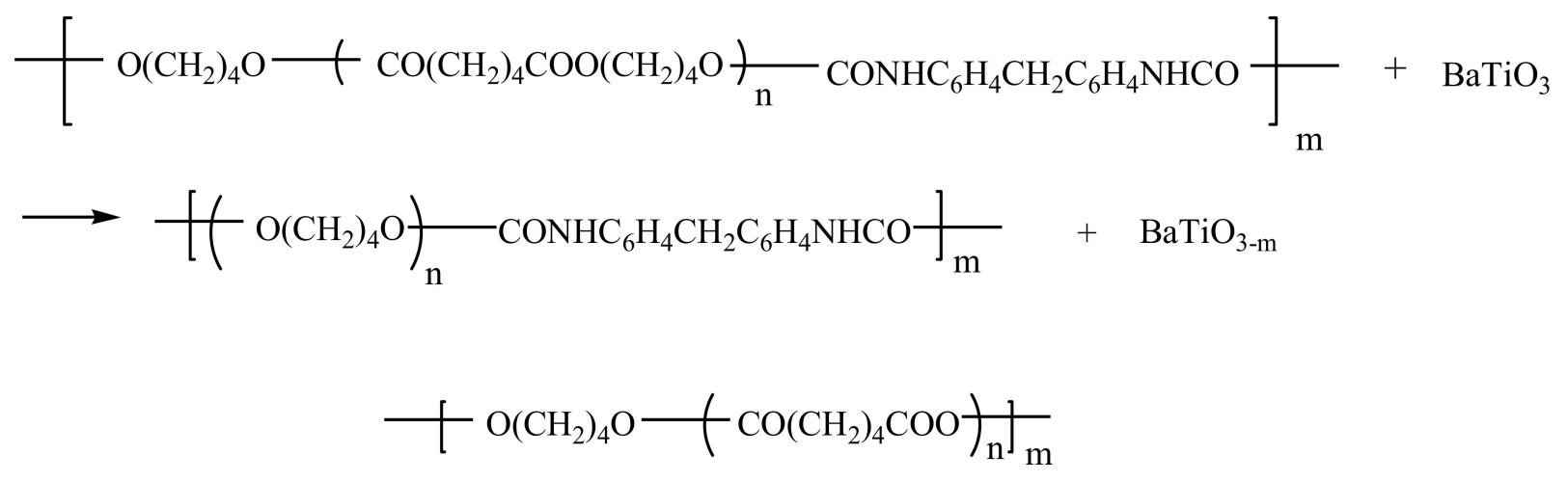

Scheme 2. The exchange reaction of TPU in the presence of the $\mathrm{BaTiO}_{3} \mathrm{NPs}$. 
Regardless of the $\mathrm{BaTiO}_{3} \mathrm{NP}$ concentration in the TPU:TPO 2:1 blend, the increase in the absorbance of the IR band localized in the spectral range $750-900 \mathrm{~cm}^{-1}$ indicates the steric hindrance effects induced in the macromolecular chain of TPO as a consequence of the chemical transformations shown in Scheme 2.

\subsection{Photoluminescence Properties of the Composites Based on the TPU:TPO Blends and $\mathrm{BaTiO}_{3} \mathrm{NPS}$}

Figure 8 presents the PL spectra of TPU, TPO, and the $\mathrm{BaTiO}_{3} \mathrm{NPs}$ recorded at the excitation wavelength equal to $350 \mathrm{~nm}$. The PL spectra of TPU, TPO, and the $\mathrm{BaTiO}_{3} \mathrm{NPs}$ showed a band with the maximum centered at $412 \mathrm{~nm}$ (Figure 8a), $441 \mathrm{~nm}$ (Figure 8b), and $530 \mathrm{~nm}$ (Figure 8c), respectively. The PL band of TPU at $412 \mathrm{~nm}$ (Figure 8a) was situated very close to the PL band of polyurethanes containing diphenylmethane $4,4^{\prime}$ diisocyante at $412 \mathrm{~nm}$ [46]. The origin of the PL band of TPU is probably due to the intrinsic chromophore centers based on benzene rings and carbonyl groups from the urethan segment of TPU, determining the appearance of a strong intensity of $\sim 3.97 \times 10^{6}$ counts/s. Contrary to expectation, TPO also showed a strong PL band, reaching a maximum intensity of $\sim 2.38 \times 10^{6}$ counts/s, even if the intrinsic chemical structure did not have luminous centers. However, one possible speculation of this result may be the material surface oxidation or the formation of extrinsic carbonyl groups at the TPO surface due to the recorded PL spectrum under normal conditions, namely in the presence of $\mathrm{O}_{2}$ and water vapor. A strong PL was also observed in polyethylene and propylene $[47,48]$ and the explanation was reported taking into account the susceptibility of $\mathrm{O}_{2}$ in the air to the surface of these polymers.

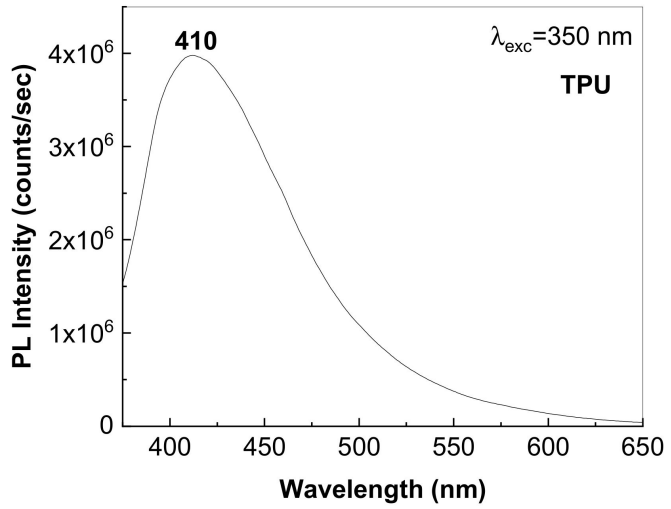

(a)

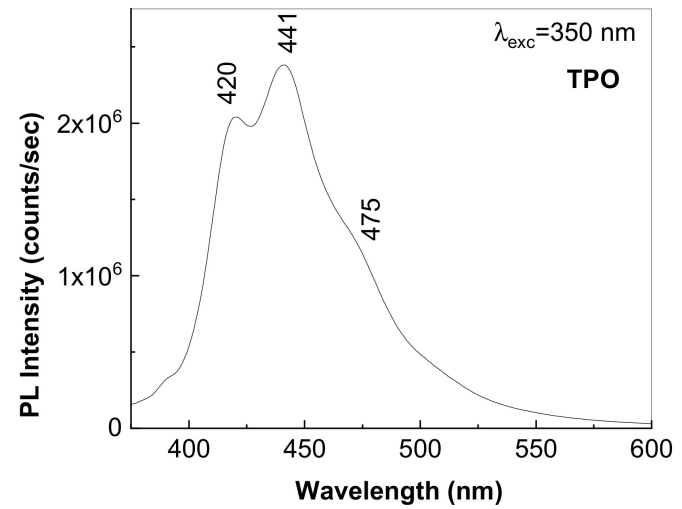

(b)

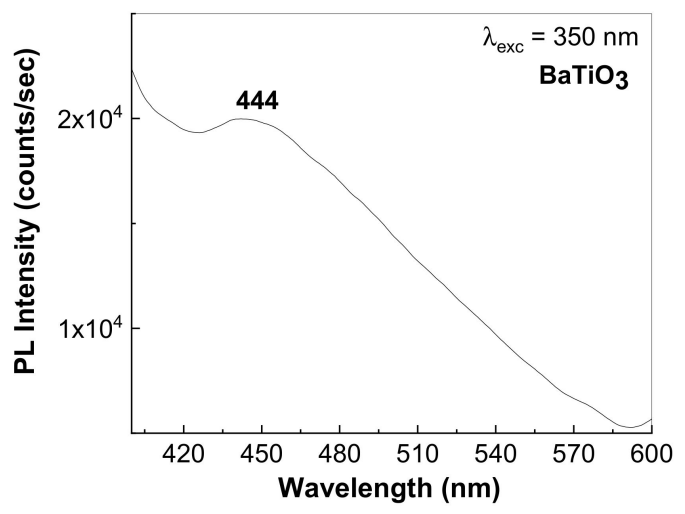

(c)

Figure 8. Photoluminescence (PL) spectra of: TPU (a), TPO (b), and the $\mathrm{BaTiO}_{3} \mathrm{NPs}_{(\mathbf{c}) \text {. }}$ 
In turn, the broad $\mathrm{PL}$ band of $\mathrm{BaTiO}_{3}$ in the visibly wide range has also been reported in the literature $[49,50]$, and was attributed to the electron-hole recombination from the predominant $\mathrm{TiO}_{6}$ clusters observed in the ordered crystalline structure of $\mathrm{BaTiO}_{3}$ responsible for the weak PL band of the material [50]. From a careful analysis of Figures 8 and 9, the PL band becomes wider for films based on the TPU: TPO blends than the TPU and TPO counterparts, most probably due to the intermembrane transitions and interconnected effects between TPU and TPO. Figure 9 shows the dependence of the PL spectra of the films based on the TPU:TPO blends with the TPU concentration in the mixture of the two thermoplastic polymers. The following variations are highlighted in Figure 9: (i) an enhancement in the intensity of PL spectra of the TPU:TPO 2:1, TPU:TPO 4:1, and TPU:TPO 6:1 blends of 1.25, 4, and 7 times higher than that of the TPU-TPO 1:1 and (ii) a down-shift of the maximum of the emission band from $486 \mathrm{~nm}$ to $462 \mathrm{~nm}, 433 \mathrm{~nm}$ and $425 \mathrm{~nm}$, when the concentration of TPU increased in the mixtures of the two thermoplastic polymers labeled TPU:TPO 1:1, TPU:TPO 2:1, TPU:TPO 4:1, and TPU:TPO 6:1, respectively. The intensity of the PL spectrum of the TPU:TPO 2:1 blend with the maximum at $462 \mathrm{~nm}$ was equal to $3.01 \times 10^{7}$ counts/s (red curve in Figure 9).

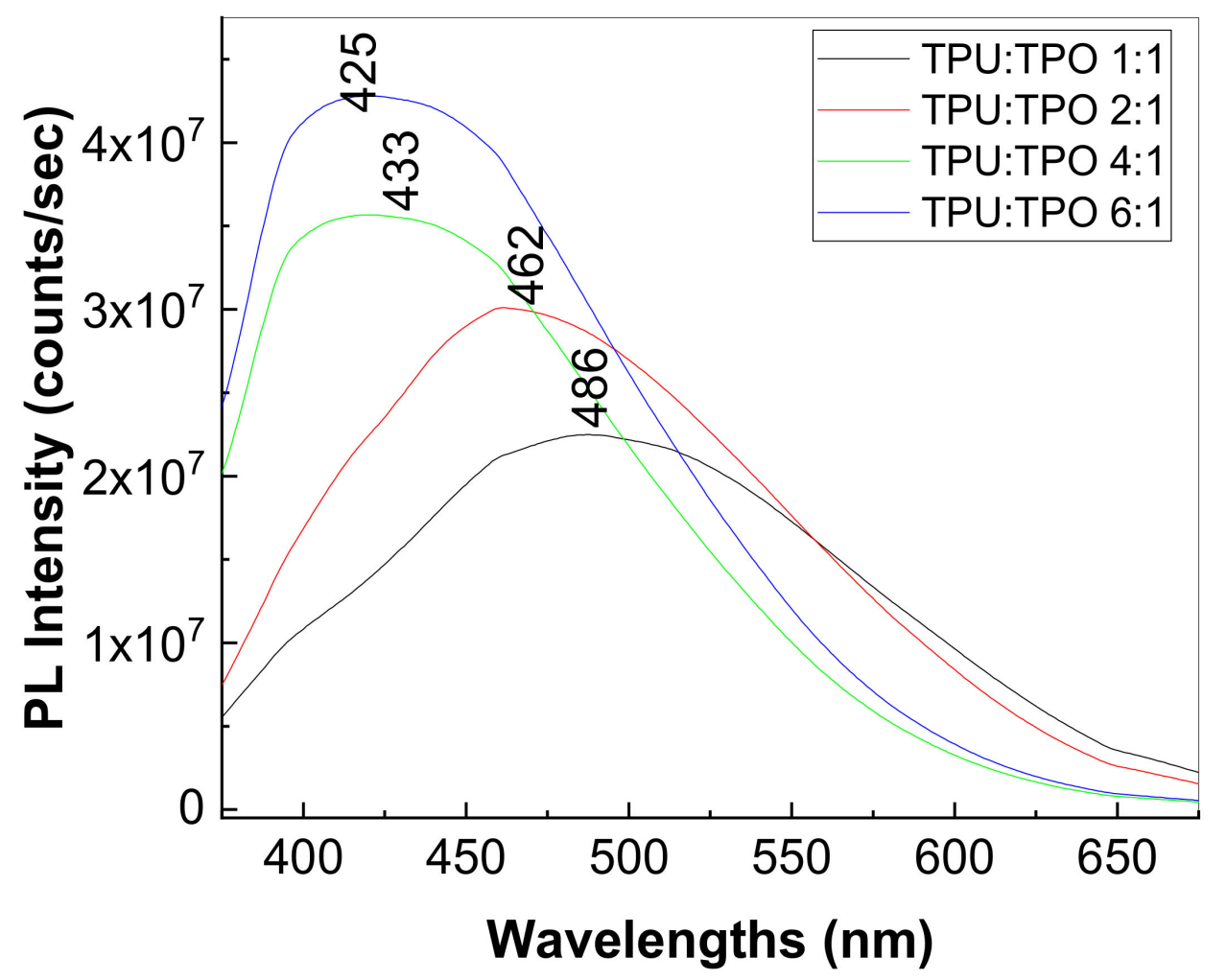

Figure 9. PL spectra $\left(\lambda_{\text {exc }}=350 \mathrm{~nm}\right.$ ) of the TPU:TPO blends having the mass ratio equal to 1:1 (black curve), 2:1 (red curve), 4:1 (green curve), and 6:1 (blue curve).

As the $\mathrm{BaTiO}_{3} \mathrm{NP}$ concentration in the TPU:TPO 2:1 blend increased, the following variations can be observed in Figure 10: (i) a gradual down-shift of the PL band to 459, 445, 439 , and $420 \mathrm{~nm}$, when the concentration of $\mathrm{BaTiO}_{3} \mathrm{NPs}$ in the TPU:TPO blend was equal to $6.25,12,25$, and $30 \mathrm{wt} . \%$, respectively; and (ii) a progressive decrease in the intensity of the PL band at $2.85 \times 10^{7}, 1.6 \times 10^{7}, 8.41 \times 10^{6}$, and $5 \times 10^{6}$ counts $/ \mathrm{s}$, when the concentration of $\mathrm{BaTiO}_{3} \mathrm{NPs}$ in the TPU:TPO blend was equal to $6.25,12,25$, and $30 \mathrm{wt} . \%$, respectively. 


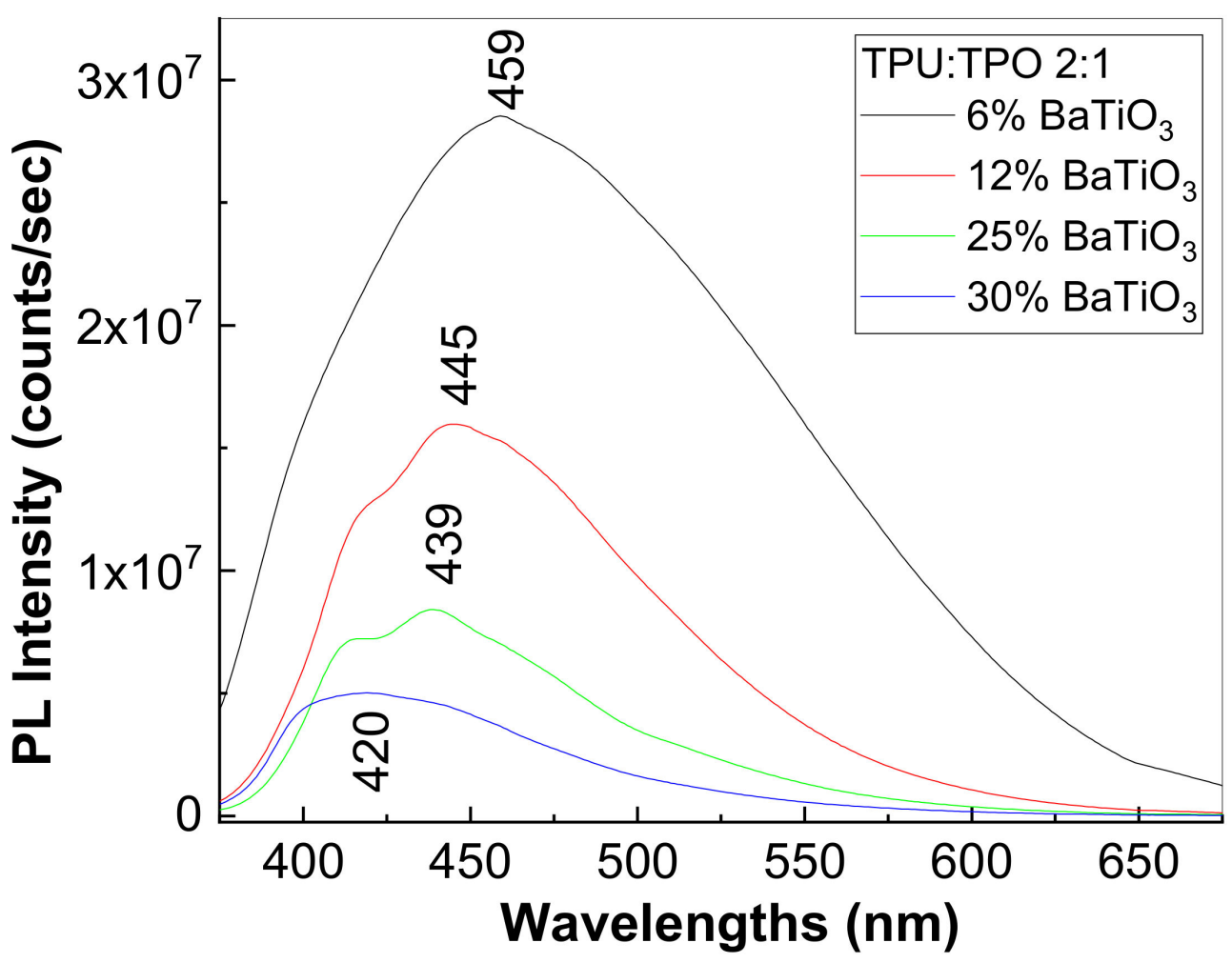

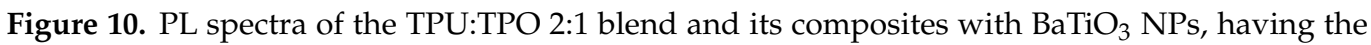
concentration of 6.25 wt.\% (black curve), 12 wt.\% (red curve), 25 wt.\% (blue curve), and 30 wt.\% (green curve).

These changes have their origin in the recrystallization process of $\mathrm{BaTiO}_{3} \mathrm{NPs}$ in the matrix of thermoplastic polymers, when an uneven crystallization and aggregation of the $\mathrm{BaTiO}_{3} \mathrm{NPs}$ in different places of the membrane matrix and/or the interfacial electron transfer efficiency between $\mathrm{BaTiO}_{3}$ and the TPU:TPO blends occurs.

A down-shift of the PL band of the film based on the TPU:TPO 4:1 blend and $\mathrm{BaTiO}_{3}$ NPs with the concentration of $12 \mathrm{wt} . \%$ was noted to take place from $433 \mathrm{~nm}$ (green curve in Figure 9) to $425 \mathrm{~nm}$ (Figure 11). This behavior was not observed in the case of the film based on the TPU:TPO 6:1 blend and the $\mathrm{BaTiO}_{3}$ NPs with the concentration of $12 \mathrm{wt} . \%$. In both cases, as shown in Figure 11, the presence of $\mathrm{BaTiO}_{3} \mathrm{NPs}$ induced a decrease in the intensity of the PL band of the TPU:TPO 4:1 and TPU:TPO 6:1 blends. This process is more intense when the TPU weight in the TPU:TPO blend increases. An explanation for this process must consider the intrinsic influence of the chromophore groups of TPU. Considering the intermolecular interaction in TPU, the $\pi$ electrons of the phenyl rings in the adjacent urethane segments located above and below the TPU sheets tend to overlap with an increase in the TPU concentration in the composite films, thus favoring these non-covalent interactions. Moreover, the $\pi-\pi$ interactions of phenyl groups are connected with the carbonyl units coming from the intrinsic chemical structure of TPU, being stabilized and isolated by the surrounding polyolefins segments similar to a coiled membrane. This explanation takes into account the PL generation of polymers [51]. High-mobility $\pi$ electrons absorb more light and therefore emit a strong PL after relaxation of the photoexcited electrons. We suppose that this is the reason why the PL is suppressed at a low concentration of TPU in the TPU:TPO blends as well as in the films based on the TPU:TPO blends and $\mathrm{BaTiO}_{3} \mathrm{NPs}$. 


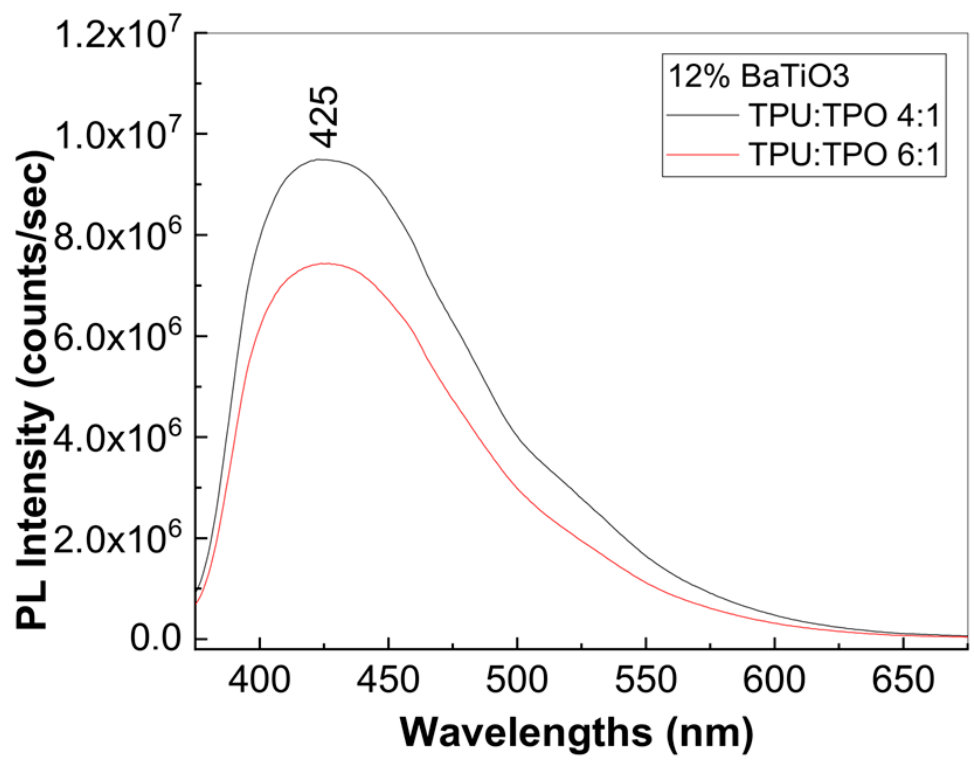

Figure 11. PL spectra of the films containing the $\mathrm{BaTiO}_{3} \mathrm{NPs}$ with the concentration of $12 \mathrm{wt} . \%$ and blends labeled TPU:TPO 4:1 (black curve) and TPU:TPO 6:1 (red curve).

\subsection{Dielectric Properties of the Composites Based on the TPU:TPO Blends and $\mathrm{BaTiO}_{3} \mathrm{NPS}$}

The studied samples show a great variation of the real and imaginary components of the complex dielectric permittivity, $\varepsilon *=\varepsilon \prime-i \varepsilon^{\prime \prime}$, both depending on the frequency and concentration of the $\mathrm{BaTiO}_{3} \mathrm{NPs}$. The real part, $\varepsilon$, is called the dielectric constant while the imaginary part, $\varepsilon^{\prime \prime}$, is called the dielectric loss. In order to observe the influence of the composition of the sample through the concentration of the $\mathrm{BaTiO}_{3} \mathrm{NPs}$, we chose an electrical quantity suitable for this purpose. Experimental data on electrical properties of the films containing the TPO:TPU blends and $\mathrm{BaTiO}_{3} \mathrm{NPs}$ are suggested by means of dielectric loss spectra depending on the frequency: $\varepsilon^{\prime \prime}=\varepsilon^{\prime \prime}(f)$, or $\varepsilon^{\prime \prime}=\varepsilon^{\prime \prime}(\omega)$, where $\omega=2 \pi f$. For both variables, the logarithmic scale is used.

The analysis of the dielectric permittivity spectra was done with the help of HavriliakNegami fitting functions $(\mathrm{H}-\mathrm{N})[52,53]$ with two components $[54,55]$ corresponding to the relaxation processes observed in graphic representations:

$$
\varepsilon_{H N}(\omega)=\left\{\varepsilon_{\infty, 1}+\frac{\Delta \varepsilon_{1}}{\left[1+\left(i \omega \tau_{\max , 1}\right)^{\alpha_{1}}\right]^{\beta_{1}}}\right\}+\left\{\varepsilon_{\infty, 2}+\frac{\Delta \varepsilon_{2}}{\left[1+\left(i \omega \tau_{\max , 2}\right)^{\alpha_{2}}\right]^{\beta_{2}}}\right\}
$$

where $\Delta \varepsilon=\varepsilon_{S}-\varepsilon_{\infty}$ is the dielectric strength; $\varepsilon_{S}=\lim _{\omega \rightarrow 0} \varepsilon l(\omega)$ and $\varepsilon_{\infty}=\lim _{\omega \rightarrow \infty} \varepsilon l(\omega)$; the characteristic time, $\tau_{\max }$, is given by the position, in frequency, of dielectric losses maxi$\operatorname{mum} \varepsilon^{\prime \prime}\left(\omega_{\max }\right)=\varepsilon_{\max }^{\prime \prime}, \varepsilon^{\prime \prime}\left(\omega_{\max }\right)=\varepsilon_{\max }^{\prime \prime}$; and the exponents $\alpha_{\mathrm{i}}$ and $\beta_{\mathrm{i}}$, called the shape parameters, influence the extension (widening) and the symmetry of the relaxation curve, around the maximum point of losses $0<\alpha_{i} \leq 1,0<\beta_{i} \leq 1$.

$\mathrm{BaTiO}_{3}$ is one of the most important ferroelectric materials with a high dielectric constant, high performance of piezoelectricity, and electro-optical effect [56]. High dielectric constant, behavior in frequency and temperature makes it a preferred material in the electronics manufacturing industry, suitable for the manufacture of ceramic miniaturized capacitor, frequency-adjustable devices, or as relaxors [57-59].

Figure 12 shows the experimental spectra of dielectric losses (black curves) and $\mathrm{H}-\mathrm{N}$ fit functions (red curves) in the case of the films containing the TPU:TPO 2:1 blend in the absence and in the presence of the $\mathrm{BaTiO}_{3} \mathrm{NPs}$ when the concentration of the inorganic compound was equal to $6.25,12,25$, and $30 \mathrm{wt} . \%$. Figure 12 indicates the existence of two maximum points in the dielectric loss spectra, which indicates the presence of two dielectric relaxation processes, one at low frequency below $3 \mathrm{~Hz}$, and the other at high frequencies 
over $50 \mathrm{kHz}$. The first dielectric relaxation process was dominant and its maximum point changed depending on the $\mathrm{BaTiO}_{3} \mathrm{NP}$ concentration. In the low frequency region, the $\mathrm{H}-\mathrm{N}$ functions have a very good overlap on the experimental data, indicating a correct fit. The shape parameters' value, exponents $\alpha_{1}$ and $\beta_{1}$, are close to the unit, indicating Debye-type dielectric relaxation processes.

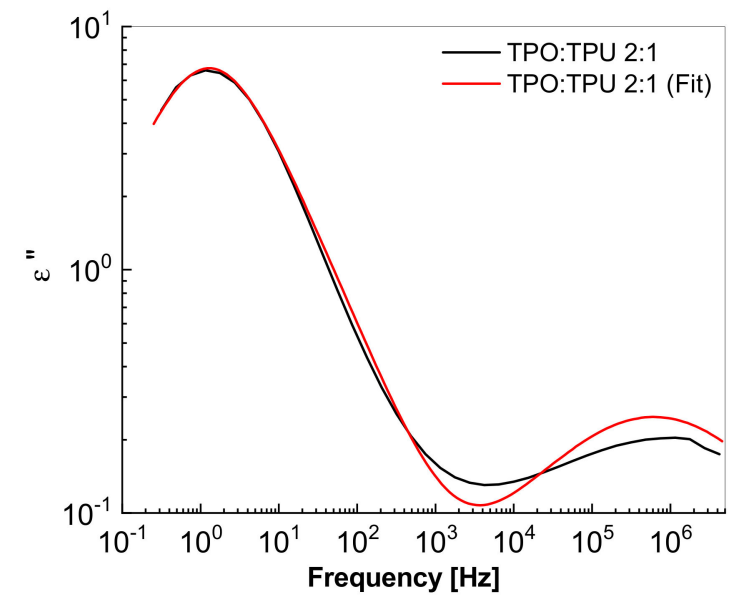

(a)

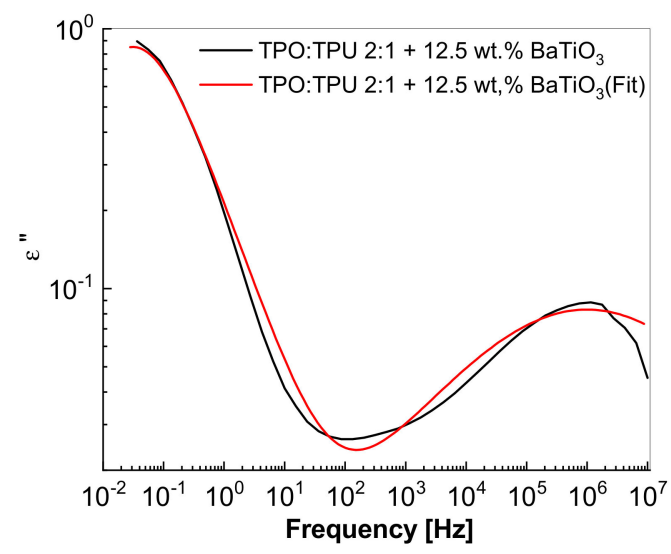

(c)

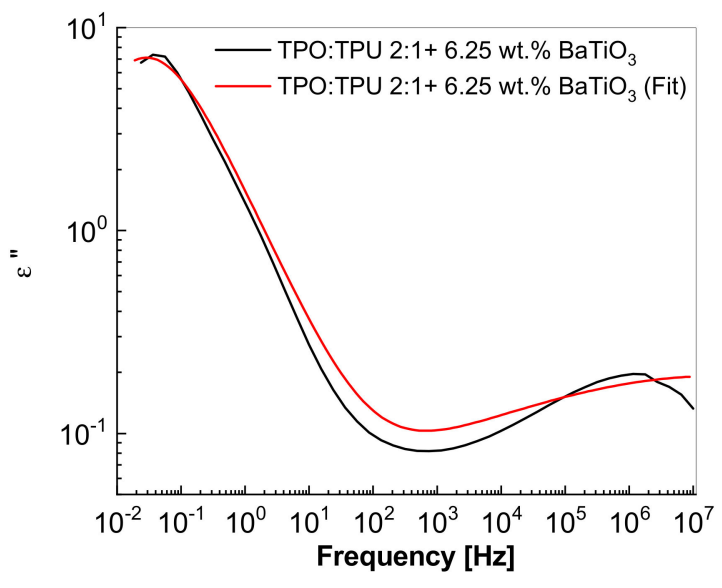

(b)

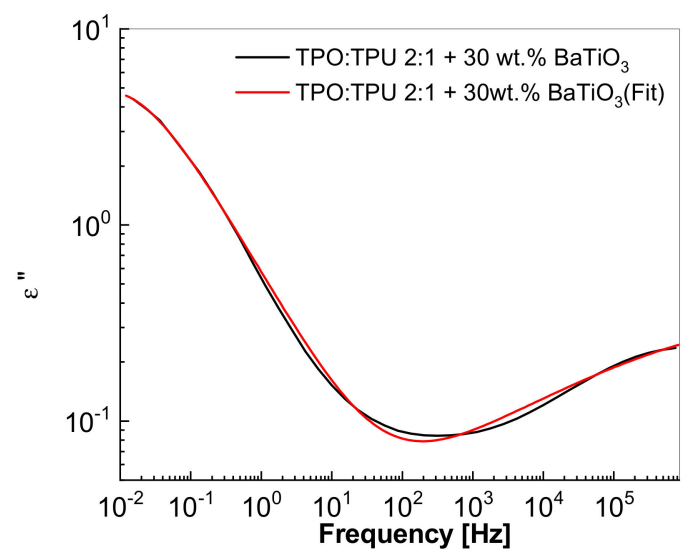

(d)

Figure 12. Dielectric loss, $\varepsilon^{\prime \prime}=\varepsilon^{\prime \prime}(f)$, of the films containing (a) the TPO:TPU 2:1 blend as well as the TPO:TPU 2:1 blends and various concentrations of $\mathrm{BaTiO}_{3}$ NPs as follows: (b) $6.25 \mathrm{wt.} \%$, (c) $12.5 \mathrm{wt} \%$, and (d) 30 wt.\%. The black curve represents the experimental data and the red curve is the fitting function.

In the order to observe the influence of the concentration of the $\mathrm{BaTiO}_{3} \mathrm{NPs}$ on the electrical properties of the TPU:TPO 2:1 blends, we superimposed on the same graph the spectra of dielectric losses for all the studied samples in Figure 13. The spectrum of the TPO:TPU 2:1 blend showed a maximum point at a frequency of about $2 \mathrm{~Hz}$ (black curve). From Figure 13, it can be observed that the maximum point "moves" to a lower frequency when the concentration of $\mathrm{BaTiO}_{3} \mathrm{NPs}$ increased. Characteristic time, $\tau_{\max }$, is an important parameter of the dielectric relaxation process. It has two properties that make it important to consider: (a) its value does not depend on the geometric dimension of the sample; in other words, the measurement error for the sample thickness or diameter does not influence it; and (b) the maximum point location in the dielectric loss spectra, with the help of fitting functions, is done with highest precision in comparison with other dielectric relaxation process parameters; the fitted value of relaxation time has the highest confidence. 


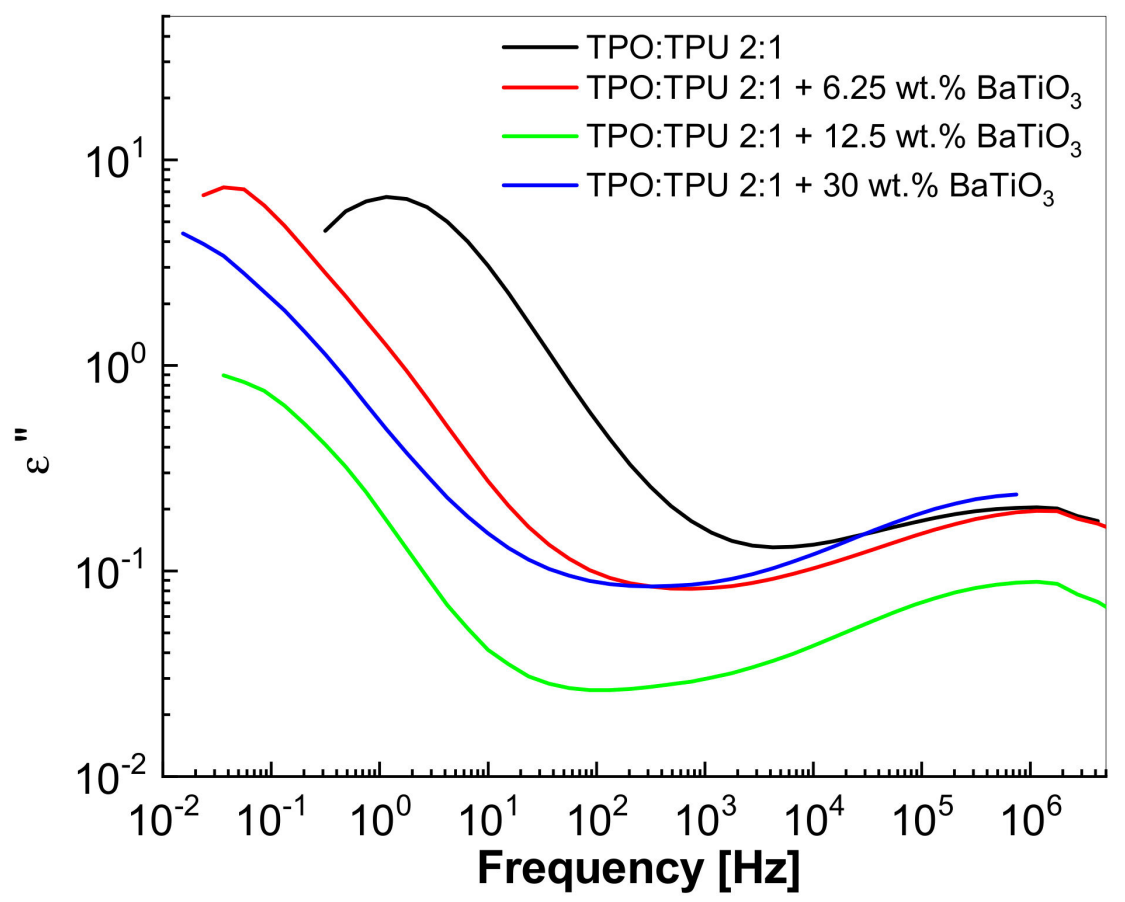

Figure 13. Superimposed dielectric loss spectra, $\varepsilon^{\prime \prime}=\varepsilon^{\prime \prime}(f)$, for TPO:TPU 2:1 samples with different $\mathrm{BaTiO}_{3}$ NP concentrations: $6.25,12,25$, and $30 \mathrm{wt} . \%$.

Figure 14 shows the correspondence that exists between the change in the characteristic time value and the increase in the $\mathrm{BaTiO}_{3} \mathrm{NP}$ concentration in the structure of the TPU:TPO 2:1 blend.

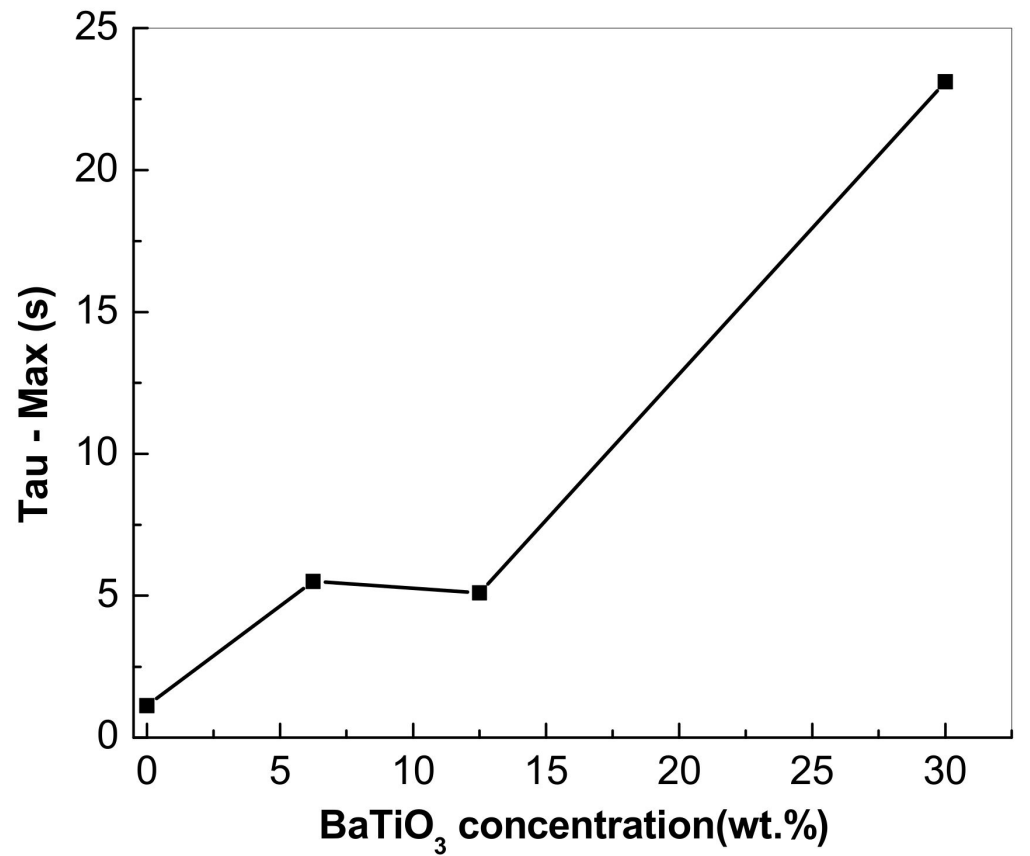

Figure 14. Time characteristic dependence of the TPU:TPO 2:1 blend on the $\mathrm{BaTiO}_{3} \mathrm{NP}$ concentration: $6.25,12,25$ and $30 \mathrm{wt} . \%$.

The experimental results allowed us to assume that the dielectric relaxation processes are dipolar in nature. We considered the electric dipoles of some segments of the polymer chain and the permanent electric dipoles of the $\mathrm{BaTiO}_{3} \mathrm{NPs}$. The shape of the dielectric 
permittivity spectra depends on the interaction between the two electrical moments of the TPU:TPO 2:1 host matrix and the $\mathrm{BaTiO}_{3}$ guest NPs. As the concentration of $\mathrm{BaTiO}_{3}$ NPs increases, the interaction energy with the polymer chain (segments) increases, which causes the host molecular mobility to decrease. The effect is to increase the characteristic time of the TPU:TPO 2:1 blend with the increase in $\mathrm{BaTiO}_{3} \mathrm{NP}$ concentration.

3.5. Differential Scanning Calorimetry (DSC) Study of the Composites Based on the TPU:TPO Blends and $\mathrm{BaTiO}_{3} \mathrm{NPs}$

Figure 15 shows the DSC curves of the TPU:TPO 2:1 blend and their composites with $\mathrm{BaTiO}_{3} \mathrm{NPs}$.

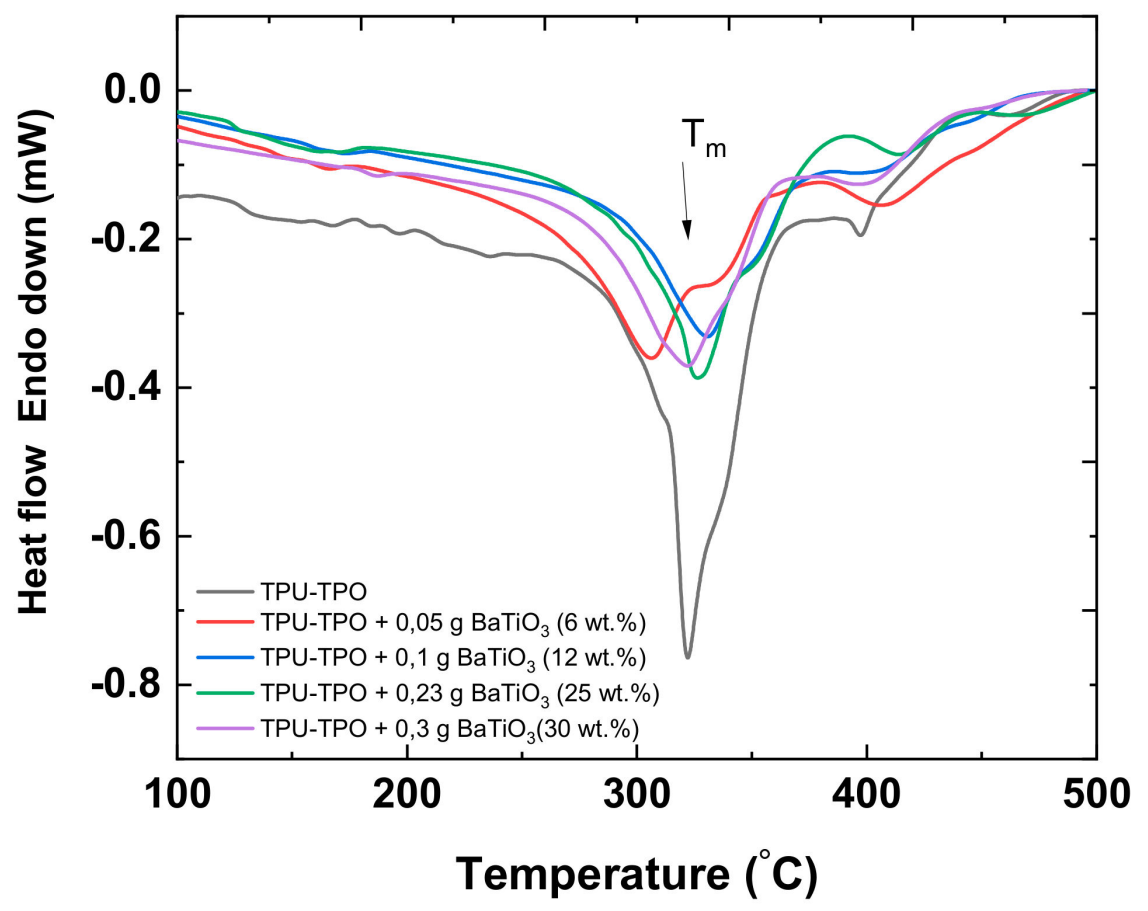

Figure 15. Differential scanning calorimetry (DSC) curves of the TPU:TPO 2:1 blend (black curve) and their composites with $\mathrm{BaTiO}_{3} \mathrm{NPs}$, the inorganic compound concentration being equal to 6.25 wt. $\%$ (red curve), 12 wt.\% (blue curve), 25 wt.\% (green curve), and 30 wt.\% (magenta curve).

According to Figure 15, the results of the DSC analysis showed that the incorporation of the $\mathrm{BaTiO}_{3} \mathrm{NPs}$ into the TPU:TPO matrix influenced the thermal stability of the samples. It was observed that the sample with $12 \mathrm{wt} . \% \mathrm{BaTiO}_{3}$ was the most stable, having the highest value of melting temperature $\left(\mathrm{Tm}=330.4^{\circ} \mathrm{C}\right)$. The maxima of melting peaks corresponding to the samples with $25 \mathrm{wt} . \% \mathrm{BaTiO}_{3}$ and $30 \mathrm{wt} . \% \mathrm{BaTiO}_{3}$ were very close (Table 1), but lower than that of the sample with $12 \mathrm{wt} . \% \mathrm{BaTiO}_{3}$.

Table 1. The melting parameters estimated from the differential scanning calorimetry (DSC) endothermic curves of the TPU:TPO 2:1 blend and their composites with $\mathrm{BaTiO}_{3} \mathrm{NPs}_{\text {. }}$

\begin{tabular}{ccc}
\hline Sample & Melting Temperature (Max.) $\left[{ }^{\circ} \mathbf{C}\right]$ & $\begin{array}{c}\text { Enthalpy }(\Delta \mathbf{H}) \\
{\left[\mathbf{J ~ g}^{-\mathbf{1}} \text { ] }\right.}\end{array}$ \\
\hline TPU:TPO & 322.1 & 76.37 \\
TPU:TPO + 6.25 wt.\% $\mathrm{BaTiO}_{3}$ & 306.5 & 36.20 \\
TPU:TPO + 12 wt. $\% \mathrm{BaTiO}_{3}$ & 330.4 & 33.14 \\
TPU:TPO + 25 wt. $\% \mathrm{BaTiO}_{3}$ & 325.8 & 38.70 \\
TPU:TPO + 30 wt. $\% \mathrm{BaTiO}_{3}$ & 326.8 & 47.38 \\
\hline
\end{tabular}


On the other hand, at $6.25 \mathrm{wt} . \% \mathrm{BaTiO}_{3}, \mathrm{Tm}=306.5^{\circ} \mathrm{C}$, lower than the melting temperature of the TPU:TPO 2:1 blend. It can be seen that the thermal stability of the TPU:TPO 2:1 blend to which was added the $\mathrm{BaTiO}_{3} \mathrm{NPs}$ did not increase proportionally to the amount of inorganic compound, but a critical amount of the $\mathrm{BaTiO}_{3} \mathrm{NPs}$ can lead to an increase in the thermal stability of the macromolecular compounds, as observed in the case of the sample TPU:TPO $+12 \mathrm{wt} . \% \mathrm{BaTiO}_{3}$. Regarding the melting enthalpies, the TPU:TPO 2:1 blend with $12 \mathrm{wt} . \% \mathrm{BaTiO}_{3}$ had the lowest value $(\Delta \mathrm{H}=33.14 \mathrm{~J} / \mathrm{g})$ confirming the stability of the material.

\section{Conclusions}

In this work, we reported new results concerning the optical, structural, and dielectric properties of the films containing the TPU:TPO blends and $\mathrm{BaTiO}_{3} \mathrm{NPs}$. Using SEM, Raman scattering, FTIR spectroscopy, photoluminescence, XRD, and dielectric analysis, the following conclusions can be drawn: (i) the SEM images highlighted that the free films of TPU and TPO are characterized by discrete phases of spherical shape, which are randomly distributed to form the cross-physical contacts between the amorphous segments of TPU and TPO; (ii) XRD analysis demonstrated that the $\mathrm{BaTiO}_{3} \mathrm{NPs}$ had a tetragonal structure that was not disturbed when they were dispersed in the films based on the TPU:TPO blends; (iii) according to the Raman scattering and FTIR spectroscopy studies, an exchange reaction was invoked to take place during the preparation of the films based on the TPU:TPO blends; in the presence of the $\mathrm{BaTiO}_{3} \mathrm{NPs}$, this exchange reaction induces the appearance in the addition of the compound $\mathrm{BaTiO}_{3-\mathrm{m}}$; (iv) an enhancement in the PL bands intensities of the TPU:TPO 2:1, TPU:TPO 4:1, and TPU:TPO 6:1 blends of 1.25, 4, and 7 times higher than that of the TPU-TPO 1:1 accompanied by a down-shift of the maximum of the emission band from $486 \mathrm{~nm}$ to $462 \mathrm{~nm}, 433 \mathrm{~nm}$ and $425 \mathrm{~nm}$, when the TPU concentration increased in the two thermoplastic polymer blends labeled TPU:TPO 1:1, TPU:TPO 2:1, TPU:TPO 4:1, and TPU:TPO 6:1, respectively, were reported; our studies indicate that the $\mathrm{BaTiO}_{3} \mathrm{NPs}$ play the role of the PL quenching agent of the TPU:TPO blends; and (v) the host matrix of the TPO:TPU 2:1 blend and their composites with the $\mathrm{BaTiO}_{3} \mathrm{NPs}_{\text {showed two distinct }}$ processes of well separated dipolar relaxation: one at low frequencies and another at high frequencies. For low frequency relaxation process, the characteristic time increased with an increase in the $\mathrm{BaTiO}_{3}$ concentration.

Author Contributions: Conceptualization, M.B., R.C., C.S., and R.G.G., Investigation, M.B., A.N., I.S., M.S., L.S., M.C., R.C.C., A.L., P.G., I.M., and C.B.; Writing-original draft preparation, M.B., A.N., and P.G.; Writing-review and editing, M.B.; Supervision, M.B. All authors have read and agreed to the published version of manuscript.

Funding: This research was funded by a grant of the Romanian National Authority for Scientific Research and Innovation-CCCDI-UEFISCDI (COFUND-ERANET MANUNET III-4DPrintEN).

Institutional Review Board Statement: Not applicable.

Informed Consent Statement: Not applicable.

Data Availability Statement: The data reported in this article are available on request from the corresponding author.

Conflicts of Interest: The authors declare no conflict of interest.

\section{References}

1. Liu, T.; Ye, L.; Liu, Y.; Nie, F. Synthesis and properties of polyester-based TPUs prepared by solution polymerisation. Plast. Rubber Compos. 2008, 37, 331-340. [CrossRef]

2. Akindoyo, J.O.; Beg, M.D.H.; Ghazali, S.; Islam, M.R.; Nitthiyah, J.; Yuvaraj, A.R. Polyurethane types, synthesis and applicationsA review. RSC Adv. 2016, 6, 114453-114482. [CrossRef]

3. Georgopoulou, A.; Sebastian, T.; Clemens, F. Thermoplastic elastomer composite filaments for strain sensing applications extruded with a fused deposition modelling 3D printer. Flex. Print. Electron. 2020, 5, 035002. [CrossRef] 
4. Rollo, G.; Ronca, A.; Cerruti, P.; Gan, X.; Fei, G.; Xia, H.; Gorokhov, G.; Bychanok, D.; Kuzhir, P.; Lavorgna, M.; et al. On the Synergistic Effect of Multi-Walled Carbon Nanotubes and Graphene Nanoplatelets to Enhance the Functional Properties of SLS 3D-Printed Elastomeric Structures. Polymers 2020, 12, 1841. [CrossRef] [PubMed]

5. Reifler, F.A.; Sánchez, F.A.; Clemens, F.J.; Varga, K.; Hufenus, R. Flexible ceramic-reinforced polyurethane composite coatings on synthetic fibres: Process of continuous liquid film coating and its influence on the coating thickness. Compos. Sci. Technol. 2010, 70, 1207-1213. [CrossRef]

6. Lavorgna, M.; Cerruti, P.; Casula, G.; Iannace, S.; Harper, J.F. Curing characteristics and mechanical properties of carbon fiber-interlayered fabric composites based on a polyurethane matrix. Adv. Polym. Technol. 2007, 26, 132-145. [CrossRef]

7. Fernández-D'Arlas, B.; Khan, U.; Rueda, L.; Coleman, J.N.; Mondragon, I.; Corcuera, M.A.; Eceiza, A. Influence of hard segment content and nature on polyurethane/multiwalled carbon nanotube composites. Compos. Sci. Technol. 2010, 71, 1030-1038. [CrossRef]

8. Hu, S.; Shou, T.; Guo, M.; Wang, R.; Wang, J.; Tian, H.; Qin, X.; Zhao, X.; Zhang, L. Fabrication of New Thermoplastic Polyurethane Elastomers with High Heat Resistance for 3D Printing Derived from 3,3-Dimethyl-4,4'-diphenyl Diisocyanate. Ind. Eng. Chem. Res. 2020, 59, 10476-10482. [CrossRef]

9. Phua, S.L.; Yang, L.; Toh, C.L.; Huang, S.; Tsakadze, Z.; Lau, S.K.; Mai, Y.-W.; Lu, X. Reinforcement of Polyether Polyurethane with Dopamine-Modified Clay: The Role of Interfacial Hydrogen Bonding. ACS Appl. Mater. Interfaces 2012, 4, 4571-4578. [CrossRef]

10. Zo, H.J.; Joo, S.H.; Kim, T.; Seo, P.S.; Kim, J.H.; Park, J.S. Enhanced mechanical and thermal properties of carbon fiber composites with polyamide and thermoplastic polyurethane blends. Fibers Polym. 2014, 15, 1071-1077. [CrossRef]

11. Guo, Y.; Yan, L.; Zheng, Z.; Chen, L.; Ma, M.; Luo, R.; Bian, J.; Lin, H.; Chen, D. TPU/PLA nanocomposites with improved mechanical and shape memory properties fabricated via phase morphology control and incorporation of multi-walled carbon nanotubes nanofillers. Polym. Eng. Sci. 2020, 60, 1118-1128. [CrossRef]

12. Qi, S.; Fu, J.; Xie, Y.; Li, Y.; Gan, R.; Yu, M. Versatile magnetorheological plastomer with 3D printability, switchable mechanics, shape memory, and self-healing capacity. Compos. Sci. Technol. 2019, 183, 107817. [CrossRef]

13. Di, Y.; Kang, M.; Zhao, Y.; Yan, S.; Wang, X. Morphology and mechanical properties of blends of thermoplastic polyurethane and polyolefins. J. Appl. Polym. Sci. 2006, 99, 875-883. [CrossRef]

14. Jeong, B.Y.; Choi, M.J.; Lee, W.-K.; Chun, J.H.; Cheon, J.M.; Ha, C.-S. Preliminary studies of polyurethane adhesive for thermoplastic polyolefins(TPOs) using polyolefin polyol. Mol. Cryst. Liq. Cryst. 2018, 660, 115-120. [CrossRef]

15. Burnett, D.J.; Thielmann, F.; Ryntz, R.A. Correlating thermodynamic and mechanical adhesion phenomena for thermoplastic polyolefins. J. Coat. Technol. Res. 2007, 4, 211-215. [CrossRef]

16. Deng, K.; Felorzabihi, N.; Winnik, M.A.; Jiang, Z.; Yin, Z.; Liu, Y.; Yaneff, P.V.; Ryntz, R.A. Influence of position and composition on adhesion to injection-molded TPO plaques as model automotive parts. Polymer 2009, 50, 5084-5093. [CrossRef]

17. Kim, T.K.; Kim, B.K.; Lee, S.Y.; Cho, Y.L.; Kim, M.S.; Jeong, H.M. Thermoplastic polyurethane elastomer/thermoplastic polyolefin elastomer blends compatibilized with a polyolefinic segment in TPU. Macromol. Res. 2010, 18, 177-184. [CrossRef]

18. Wang, J.S.; Chen, X.D.; Zhang, M.Q.; Rong, M.Z. Polyurethane/Polyolefin Blends: Morphology, Compatibilization and Mechanical Properties. Polym. Polym. Compos. 2006, 14, 1-11. [CrossRef]

19. Lin, T.A.; Lou, C.-W.; Lin, J.-H. The Effects of Thermoplastic Polyurethane on the Structure and Mechanical Properties of Modified Polypropylene Blends. Appl. Sci. 2017, 7, 1254. [CrossRef]

20. Fan, B.H.; Zha, J.W.; Wang, D.R.; Zhao, J.; Zhang, X.F.; Dang, Z.M. Preparation and dielectric behaviors of thermoplastic and thermosetting polymer nanocomposite films containing $\mathrm{BaTiO}_{3}$ nanoparticles with different diameters. Compos. Sci. Technol. 2013, 80, 66-72. [CrossRef]

21. Lu, X.; Qu, H.; Skorobogatiy, M. Piezoelectric Micro- and Nanostructured Fibers Fabricated from Thermoplastic Nanocomposites Using a Fiber Drawing Technique: Comparative Study and Potential Applications. ACS Nano 2017, 11, 2103-2114. [CrossRef] [PubMed]

22. Christ, J.F.; Aliheidari, N.; Ameli, A.; Pötschke, P. 3D printed highly elastic strain sensors of multiwalled carbon nanotube/thermoplastic polyurethane nanocomposites. Mater. Des. 2017, 131, 394-401. [CrossRef]

23. Han, H.; Voisin, C.; Guillemet-Fritsch, S.; Dufour, P.; Tenailleau, C.; Turner, C.; Nino, J.C. Origin of colossal permittivity in BaTiO3 via broadband dielectric spectroscopy. J. Appl. Phys. 2013, 113, 024102. [CrossRef]

24. Poudel, A.; Walsh, P.; Kennedy, J.; Thomas, K.; Lyons, J.G.; Coffey, A. Thermal, mechanical, dielectric, and morphological study of dielectric filler-based thermoplastic nanocomposites for electromechanical applications. J. Thermoplast. Compos. Mater. 2019, 32, 178-204. [CrossRef]

25. Sanchez, F.A.; Redondo, M.; González-Benito, J. Influence of $\mathrm{BaTiO}_{3}$ submicrometric particles on the structure, morphology, and crystallization behavior of poly(vinylidene fluoride). J. Appl. Polym. Sci. 2015, 132, 41497-41507. [CrossRef]

26. Wu, H.; Zhang, X.; Ma, Z.; Zhang, C.; Ai, J.; Chen, P.; Yan, C.; Su, B.; Shi, Y. A Material Combination Concept to Realize 4D Printed Products with Newly Emerging Property/Functionality. Adv. Sci. 2020, 7, 1903208. [CrossRef]

27. Drobny, J.G. Polyolefin-based thermoplastic elastomers. In Handbook of Thermoplastic Elastomers; Drobny, J.G., Ed.; Elsevier: Norwich, UK; New York, NY, USA, 2014; pp. 191-199. [CrossRef]

28. Finnigan, B.; Martin, D.; Halley, P.; Truss, R.; Campbell, K. Morphology and properties of thermoplastic polyurethane composites incorporating hydrophobic layered silicates. J. Appl. Polym. Sci. 2005, 97, 300-309. [CrossRef] 
29. Baştürk, E.; Madakbaş, S.; Kahraman, M.V. Improved Thermal Stability and Wettability Behavior of Thermoplastic Polyurethane/Barium Metaborate Composites. Mater. Res. 2016, 19, 434-439. [CrossRef]

30. Zhang, Z.J.; Narumi, K.; Naramoto, H.; Wu, Z.P.; Yamamoto, S.; Miyashita, A.; Tamada, M. A crystalline hydrogenated carbon film obtained by plasma enhanced chemical vapor deposition. J. Appl. Phys. 1999, 86, 1317-1321. [CrossRef]

31. Archie, L.; Robbins, L.; Mills, K.R. Compositions Comprising an Olefin Polymer, Carbon Black and Dithiobisben Zothazole and Process for Curing Same. Patent No. 770582, 1962.

32. Morris, H.R.; Turner, J.F.; Munro, B.; Ryntz, R.A.; Treado, P.J. Chemical Imaging of Thermoplastic Olefin (TPO) Surface Architecture. Langmuir 1999, 15, 2961-2972. [CrossRef]

33. Parnell, S.; Min, K.; Cakmak, M. Kinetic studies of polyurethane polymerization with Raman spectroscopy. Polymer 2003, 44, 5137-5144. [CrossRef]

34. Strenkoski, M.; Lodarczyk, D.; Piszczyk, L.; Strankowska, J. Polyurethane Nanocomposites Containing Reduced Graphene Oxide, FTIR, Raman, and XRD Studies. J. Spectrosc. 2016, 2016, 1-6. [CrossRef]

35. Venkateswaran, U.D.; Naik, V.M.; Naik, R.R. High-pressure Raman studies of polycrystalline BaTiO 3 . Phys. Rev. B 1998, 58, 14256-14260. [CrossRef]

36. Pennington, B.D.; Ryntz, R.A.; Urban, M.W. Stratification in thermoplastic olefins (TPO); photoacoustic FT-IR depth profiling studies. Polymer 1999, 40, 4795-4803. [CrossRef]

37. Gopanna, A.; Mandapati, R.N.; Thomas, S.P.; Rajan, K.P.; Chavali, M. Fourier transform infrared spectroscopy (FTIR), Raman spectroscopy and wide-angle X-ray scattering (WAXS) of polypropylene (PP)/cyclic olefin copolymer (COC) blends for qualitative and quantitative analysis. Polym. Bull. 2019, 76, 4259-4274. [CrossRef]

38. Ferry, A.; Jacobsson, P.; Van Heumen, J.; Stevens, J. Raman, infra-red and d.s.c. studies of lithium coordination in a thermoplastic polyurethane. Polymer 1996, 37, 737-744. [CrossRef]

39. Requena, S.; Lacoul, S.; Strzhemechny, Y.M. Luminescent Properties of Surface Functionalized BaTiO3 Embedded in Poly(methyl methacrylate). Materials 2014, 7, 471-483. [CrossRef] [PubMed]

40. Pattamaprom, C.; Wu, C.-H.; Chen, P.-H.; Huang, Y.-L.; Ranganathan, P.; Rwei, S.-P.; Chuan, F.-S. Solvent-Free One-Shot Synthesis of Thermoplastic Polyurethane Based on Bio-Poly(1,3-propylene succinate) Glycol with Temperature-Sensitive Shape Memory Behavior. ACS Omega 2020, 5, 4058-4066. [CrossRef] [PubMed]

41. Şen, F.; Baştürk, E.; Karadoğan, B.; Madakbaş, S.; Kahraman, M.V. Effect of Barium Titanate on the Thermal, Morphology, Surface, and Mechanical Properties of the Thermoplastic Polyurethane/Barium Titanate Composites. Polym. Plast. Technol. Eng. 2016, 55, 1325-1331. [CrossRef]

42. Nejad, S.S.; Babaie, A.; Bagheri, M.; Rezaei, M.; Abbasi, F.; Shomali, A. Effects of graphene quantum dot (GQD) on photoluminescence, mechanical, thermal and shape memory properties of thermoplastic polyurethane nanocomposites. Polym. Adv. Technol. 2020, 31, 2279-2289. [CrossRef]

43. Ning, L.; De-Ning, W.; Sheng-Kang, Y. Crystallinity and hydrogen bonding of hard segments in segmented poly(urethane urea) copolymers. Polymer 1996, 37, 3577-3583. [CrossRef]

44. Song, J.; Batra, A.; Rego, J.M.; Macosko, C.W. Polyethylene/polyurethane blends for improved paint adhesion. Prog. Org. Coat. 2011, 72, 492-497. [CrossRef]

45. Mattia, J.; Painter, P. A Comparison of hydrogen bonding and order in a polyurethane and poly(urethane-urea) and their blends with poly(ethylene glycol). Macromolecules 2007, 40, 1546-1554. [CrossRef]

46. Allen, N.S.; McKellar, J.F. Photochemical reactions in an MDI-based elastomeric polyurethane. J. Appl. Polym. Sci. 1976, 20, 1441-1447. [CrossRef]

47. Arai, T.; Hosobuchi, M.; Fuse, N.; Takeda, K.; Ohki, Y. Optical Characterization and Computational Chemical Evaluation of Electronic Localized States in Polyolefin. Electr. Eng. Jpn. 2014, 188, 1-8. [CrossRef]

48. Ito, T.; Fuse, N.; Ohki, Y. Effects of Additives, Photodegradation, and Water-tree Degradation on the Photoluminescence in Polyethylene and Polypropylene. IEEJ Trans. Fundam. Mater. 2004, 124, 624-630. [CrossRef]

49. Rastogi, M.; Kushwaha, H.S.; Vaish, R. Highly efficient visible light mediated azo dye degradation through barium titanate decorated reduced graphene oxide sheets. Electron. Mater. Lett. 2016, 12, 281-289. [CrossRef]

50. Orhan, E.; Varela, J.A.; Zenatti, A.; Gurgel, M.F.C.; Pontes, F.M.; Leite, E.R.; Longo, E.; Pizani, P.S.; Beltrán, A.; Andrés, J. Room-temperature photoluminescence of $\mathrm{BaTiO}_{3}$ : Joint experimental and theoretical study. Phys. Rev. B 2005, 71, 085113. [CrossRef]

51. Yan, J.-J.; Wang, Z.-K.; Lin, X.-S.; Hong, C.-Y.; Liang, H.-J.; Pan, C.-Y.; You, Y.-Z. Polymerizing Nonfluorescent Monomers without Incorporating and Flurescent Agent Produces Strong Fluerescent Polymers. Adv. Mater. 2012, 24, 5617-5624. [CrossRef]

52. Havriliak, S.; Negami, S. A complex plane representation of dielectric and mechanical relaxation processes in some polymers. Polymer 1967, 8, 161-210. [CrossRef]

53. Schönhals, A. Broadband Dielectric Spectroscopy; Kremer, F., Schönhals, A., Eds.; Springer: Berlin/Heidelberg, Germany, 2003.

54. Urban, S.; Gestblom, B.; Kresse, H.; Dabrowski, A. Dielectric relaxations studies of 4-n-alkyloxy-4'-cyanobiphenyls (nOCB, $\mathrm{n}=5$ divided by 8). Z. Nat. A. 1996, 51, 834-842.

55. Frunză, Ş.; Schönhals, A.; Frunza, L.; Beica, T.; Zgura, I.; Ganea, P.; Stoenescu, D. Dynamics of cyanophenyl alkylbenzoate molecules in the bulk and in a surface layer adsorbed onto aerosil. Variation of the alkyl chain. Chem. Phys. 2010, 372, 51-60. [CrossRef] 
56. Yang, J.; Deng, X.Y.; Li, J.B.; Cai, Q.; Zhang, H.T.; Wang, L.M.; Su, K.F.; Zhang, G.Q.; Wang, C. Broadband Dielectric Spectroscopy Analysis of Dielectric Properties of Barium Titanate Ceramics. Adv. Mater. Res. 2013, 744, 323-328. [CrossRef]

57. Mančić, D.; Paunović, V.; Vijatović, M.; Stojanović, B.; Živković, L. Electrical Characterization and Impedance Response of Lanthanum Doped Barium Titanate Ceramics. Sci. Sint. 2008, 40, 283-294. [CrossRef]

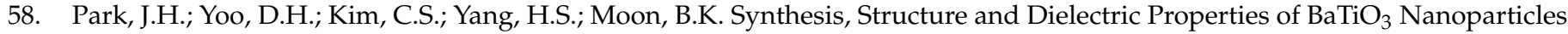
J. Korean Phys. Soc. 2006, 49, S680-S683.

59. Sareecha, N.; Shah, W.A.; Anisur-Rehman, M.; Mirza, M.L.; Awan, M.S. Electrical investigations of BaTiO 3 ceramics with Ba/Ti contents under influence of temperature. Solid State Ion 2017, 303, 16-23. [CrossRef] 